

<smiles>C1CC1</smiles> 


\section{SO $\mathrm{n}$ \\ einetit $\mathfrak{B r}$ efolechte

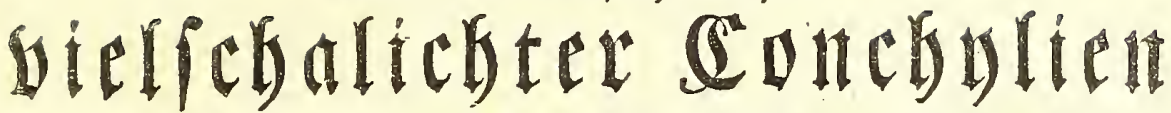 \\ mit fichetbate Belenter, \\ avelife beym sinne Cbitons beifen.}

Pine $\mathscr{A} \mathfrak{b}$ andlung

welche detl is februar I784.

bey ber $\mathfrak{\text { Berfammlung }}$

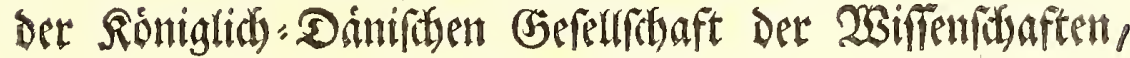

abs fie fich

mit. Der Gegentwart

Des Durblaudtigften regierenden Sergogs
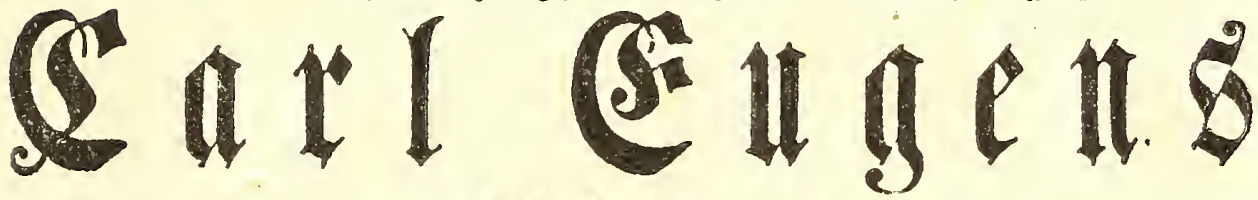

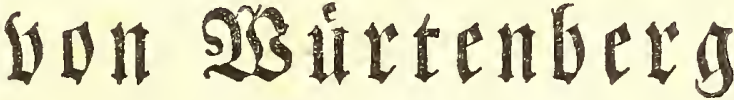

beeblet gereben vorgelefen

4no numefro ftare vermefere und ermeiter

bera

UDII

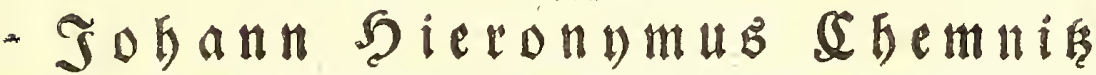

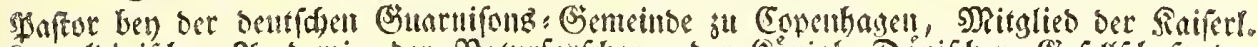

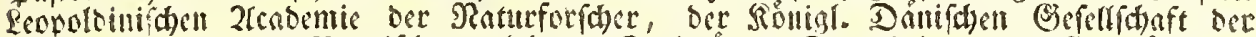

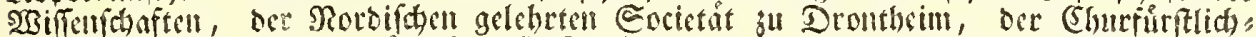

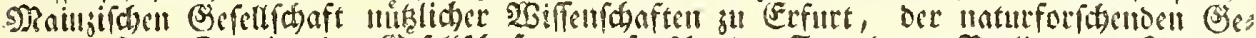

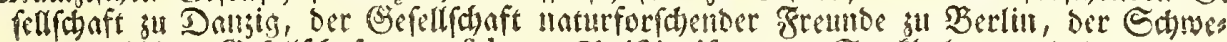

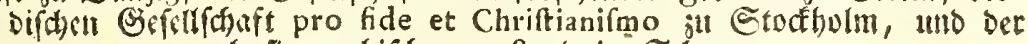

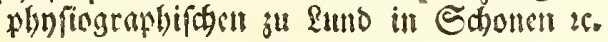

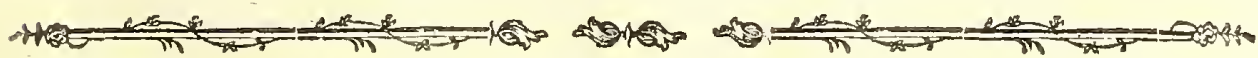

girnbergl

ben Gabriel Difolaug Rappe. I784. 


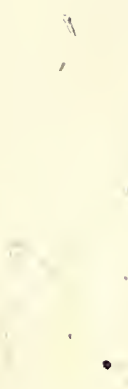

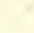




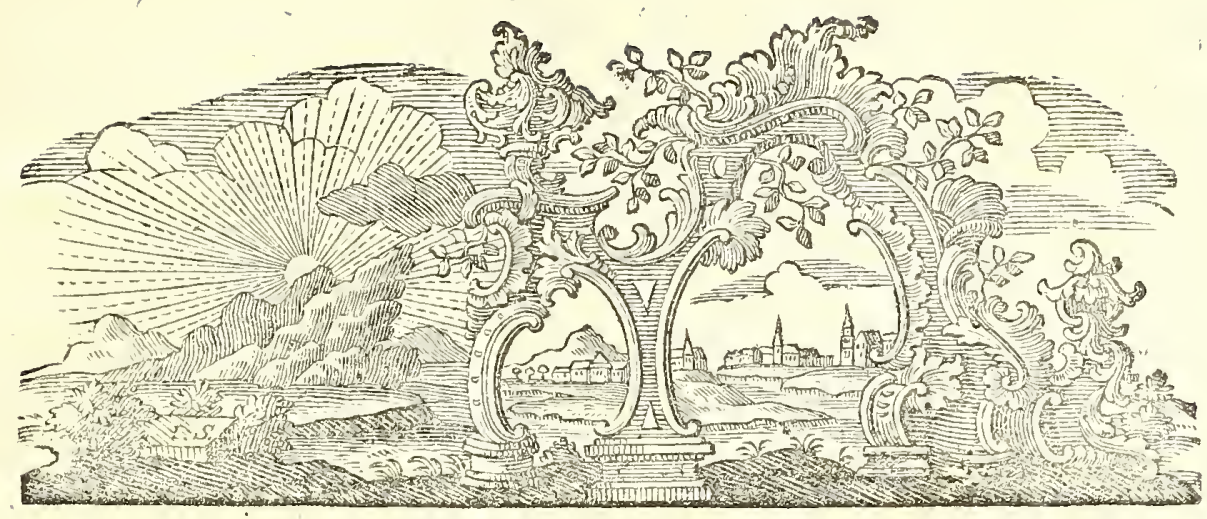

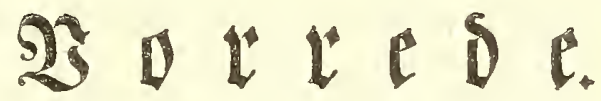

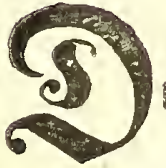

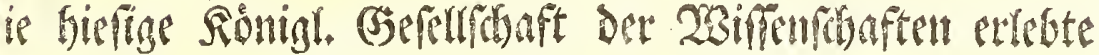

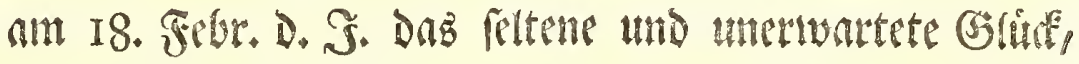

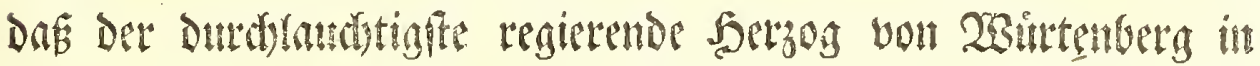

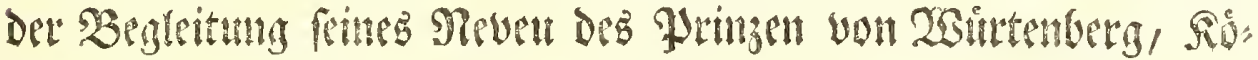

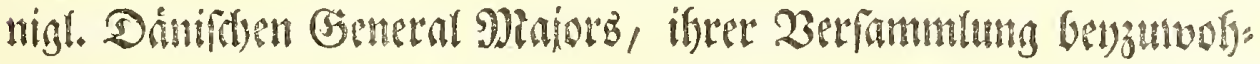

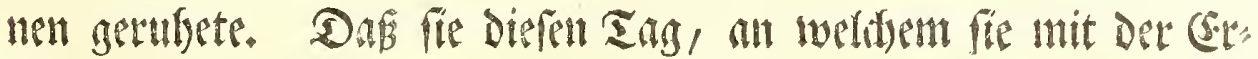

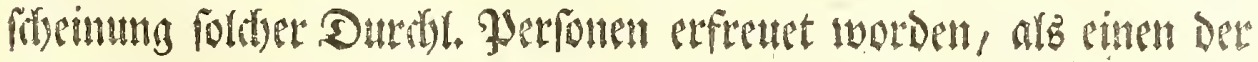

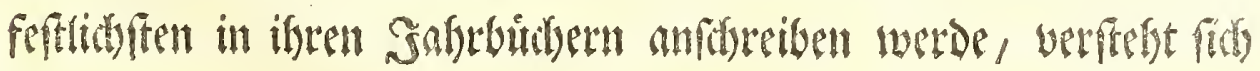




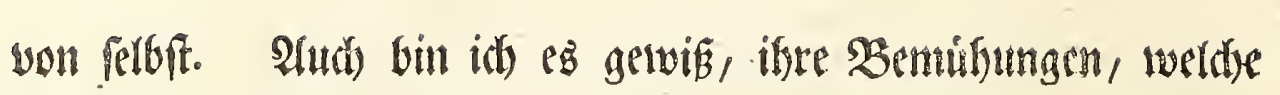
Die anfelárung mantber nod) Dunelen und swenig erbelleten shei.

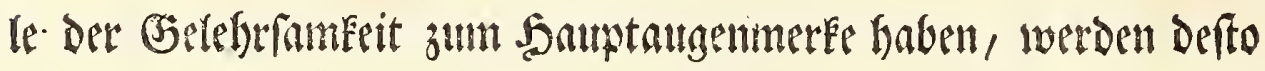
eifriger and unverdrofiner fortgefęet werden, da fie fidt Durds Den Bayfall und Durit) die Safmerefameert eines fortben Durdy). Semmers und Berefrers der Rimfte und 2 iffenfidaften fo er: muntert, belobnt und erferet fiebet.

Die Mitglieder diefer Sonigl. Dániften Bjeferfibaft Der

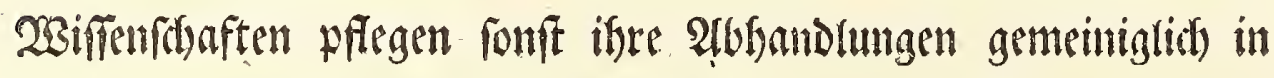
Der vaterlendiffen Spradbe, nemlith in Der Danifisen, vorzulefen,

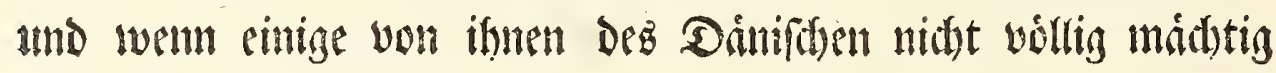

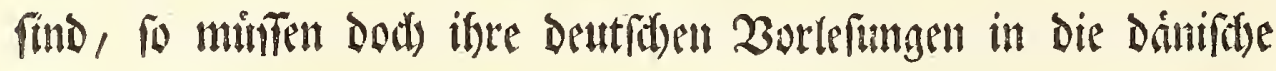

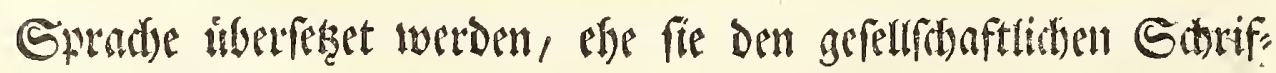

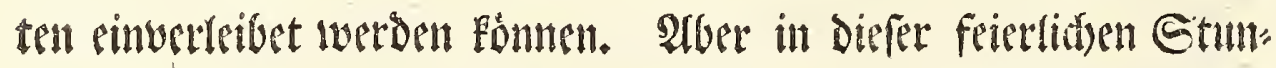
de, da ein regierender Saerzog aus einem Der ålteften, madstig"

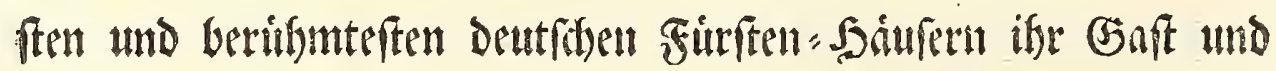

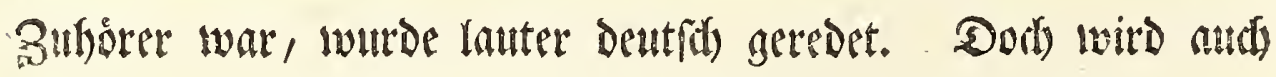

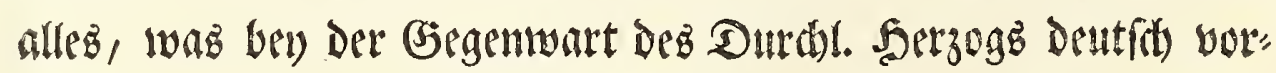
getefen und verbandelt wurds, fogleidy ins Dánifdse uberfezt mo Dann erfit den geferfochaftlityen Gibriften sinuerteibt werden. 


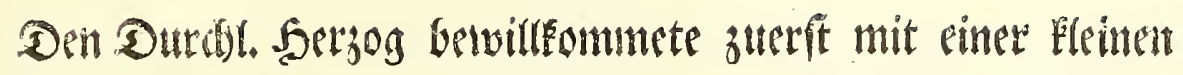

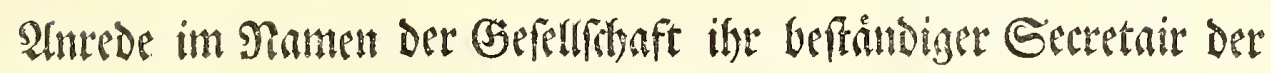

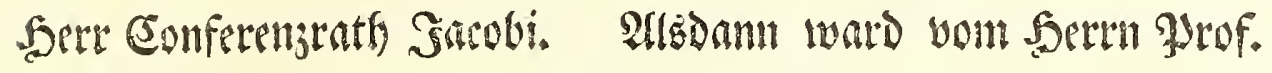

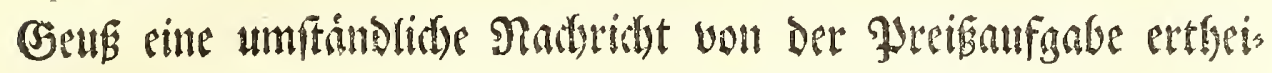

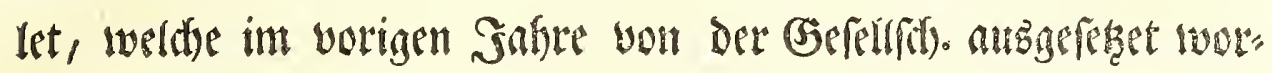

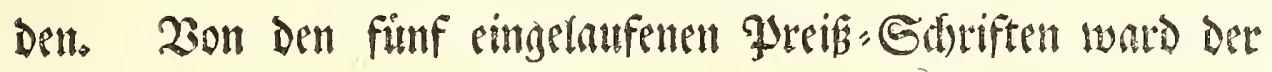

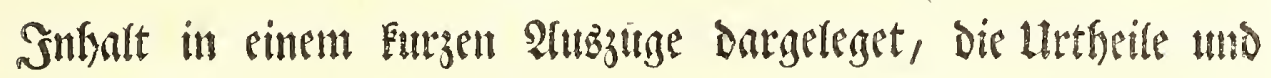
Micinungen Der zu iferer Lluterfititung ernemut gewefenen Eom, miffarien wutroen angefiffert, und endidid) Der beften mit $3^{4}$

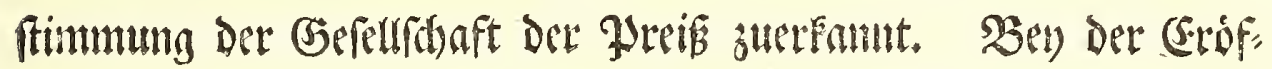

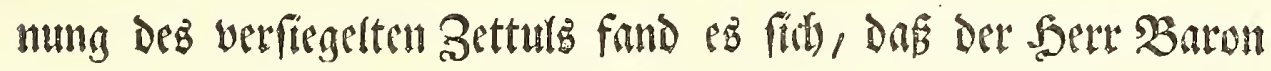

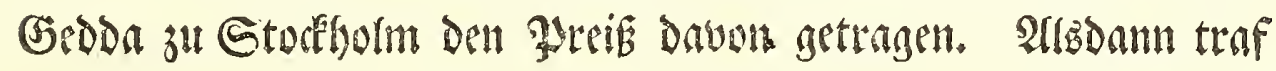

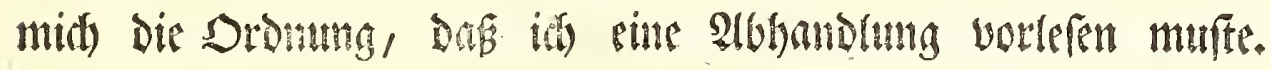

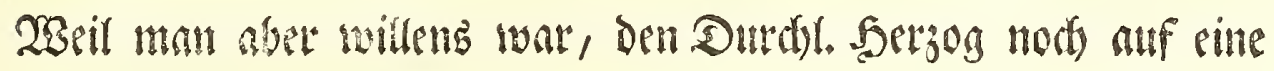

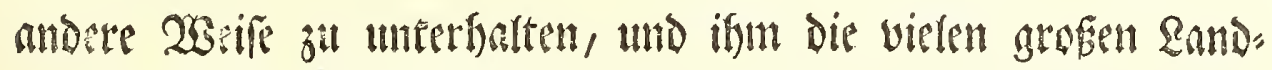

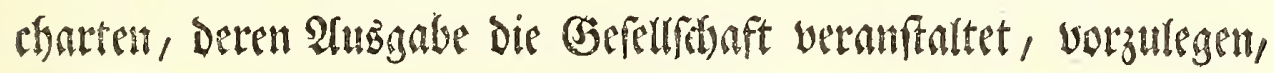
und ifmem endid) audh noib einige ber netteften (Enterefiungen, wets

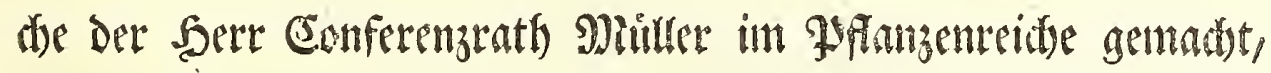
befannt zu madisen, fo fonnte und Durfte meine 3 orlefing nidat

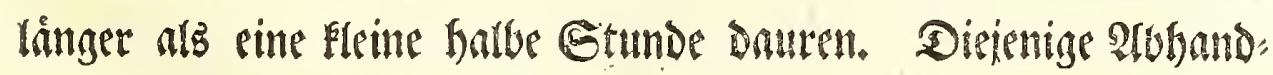

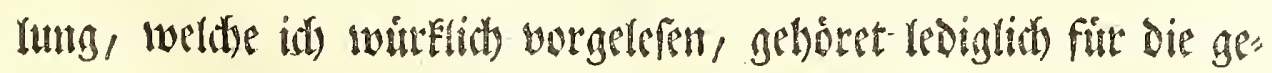

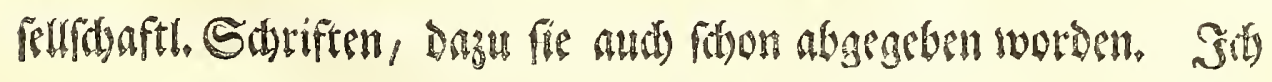

$$
\text { If } 3 \text { bate }
$$




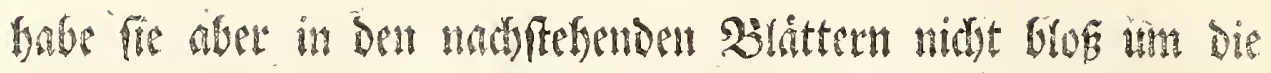

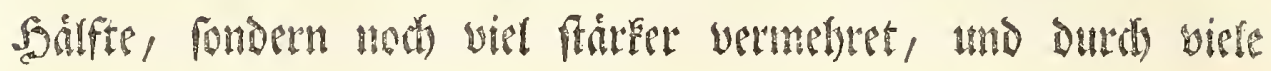

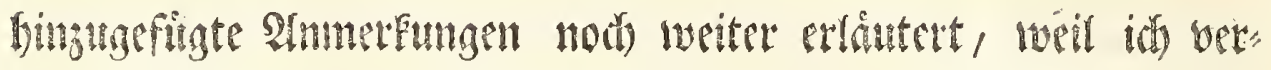

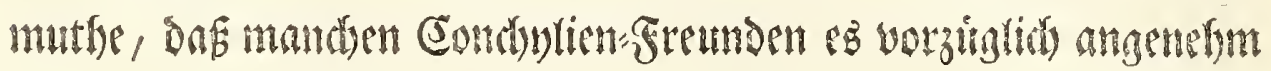

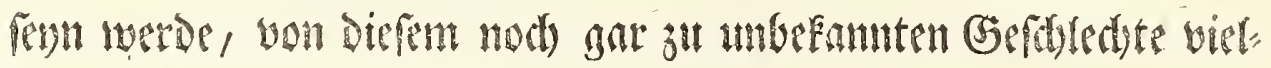

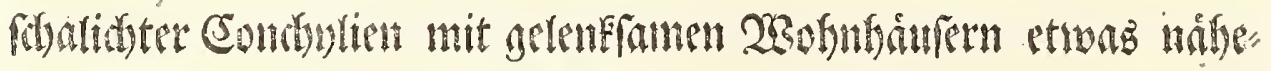

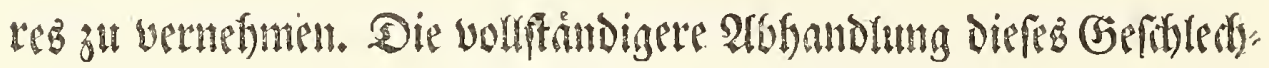

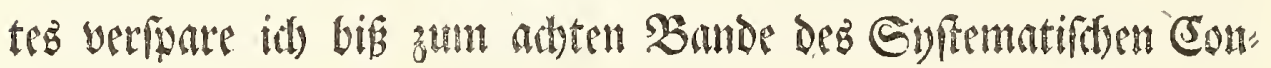

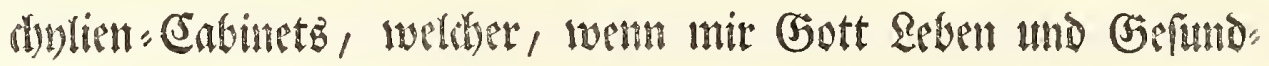

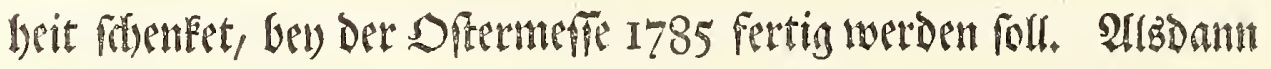

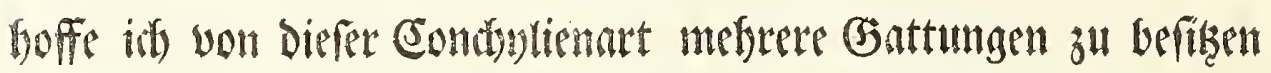
amo meine Refer befter Dowon belehren und erbauen ju Eonnen. Sopentbagen, Den 28 Februn 1784 .

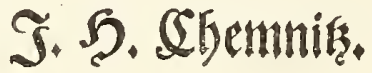

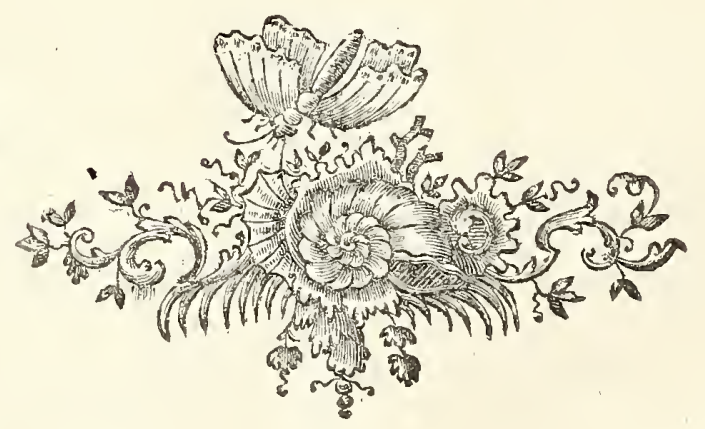

23011 


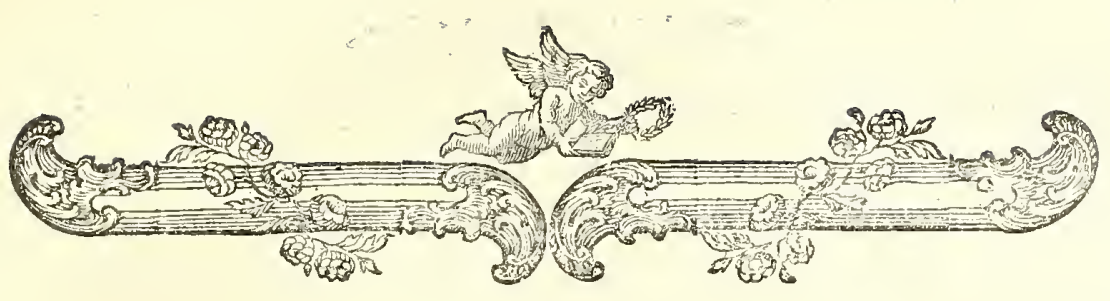

Q $\bullet \amalg$

\section{einem Befoblechte \\ wielfebaliebter Concblien \\ mit richtbaren Gelenen.}

(5.

gereidyet mir allemal jur befondern Ëgre thto Freube, wenn ith in bies

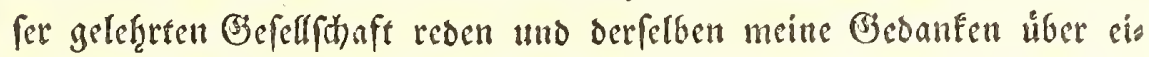

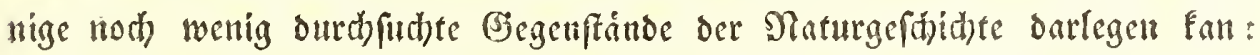

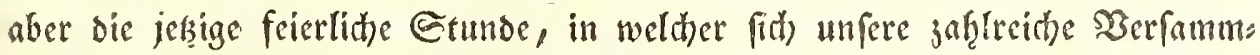
lung mit ber fiod ften Gegenwart bes burd)laudtigften regierenden Saerjogs yon 2 Burtenberg, biefes grofien Renners uno Siebhabers ber Sinfe und Sibifs

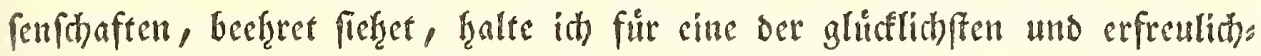
ften unter den Stunden meittes lebens. Einige Bemerfungen, die id) feit einiger Beit über cin jiemlid) unbefannes uno noch gar ju wenig unterfuth: tes (Jefthlecthe vielpdalid)ter Condbylien ju mathen und ju fanmlen Ejelegens

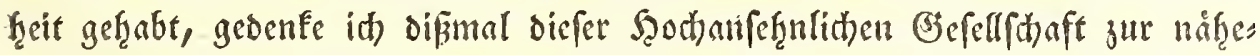

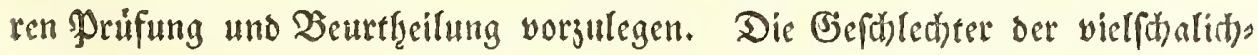

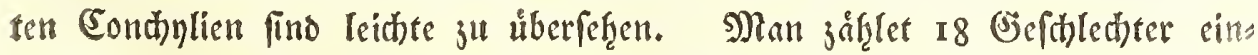
fdalid)ter, uno I4 (Befd)le(t)ter jwofhalidter Condbylien, aber man Eennes

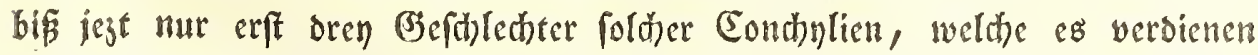
vislfhalidte, Polyconchae, teftae plurivalves, teftacea multivalvia jll heiffen, nemliớ) 


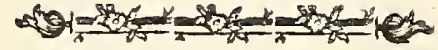

nemlich sas Gefolectit ber vom Sinne fo genannten Cefitons, fernet oet

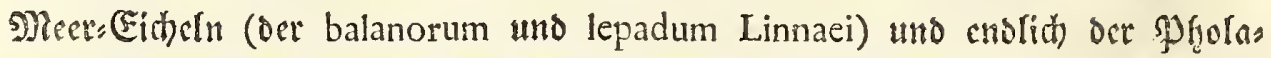

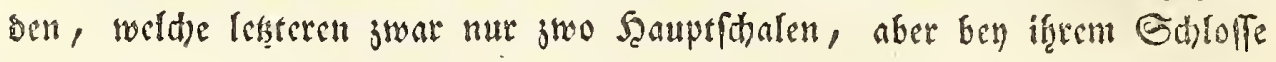
oocr Cardine mefrecre teftulas minores accerforias haben Obr. 1). Einte ming:

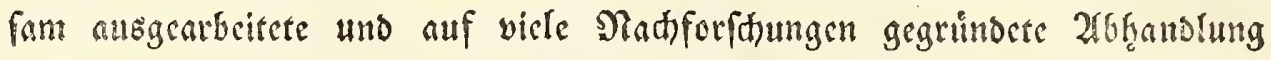

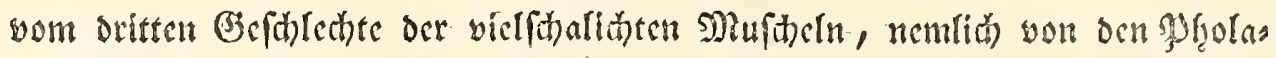
Den, warbe von meinem beften uno bewathrteften frente dem Sionigl. Serru

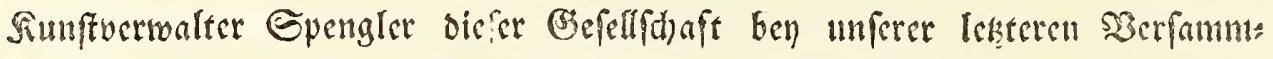
rung vorgelefen. 2ullit Naturlicbhabern and Condbliologen wird fie unge:

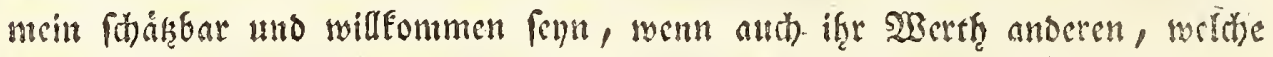

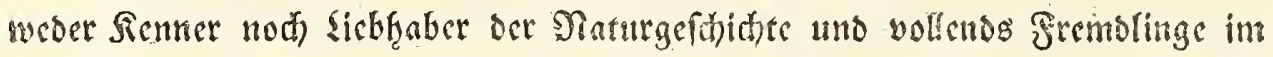

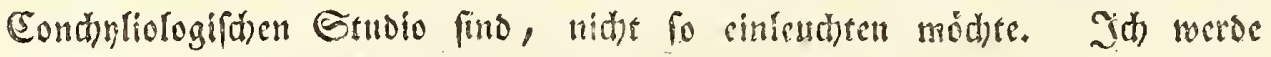

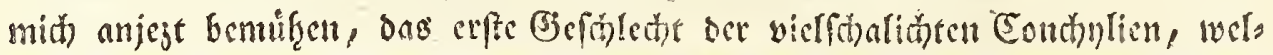

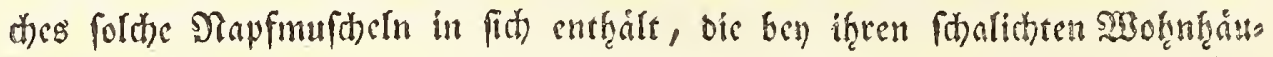
fern mit firtitbaren Gelenfen verfechen fino, cine teftam articulatam ex pluribus valvulis compofitam babcn, $11 n \mathrm{~b}$ çm Sinne Chitons heifen, cin wes nig nåfer ju betrad)ten und ju crlsutern. Mód)te fid mu cin Mlitglico

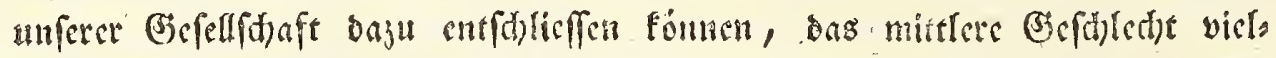
f(t)alifter (Eondynlien, id) nteine bie balanos, diefe Lepades Linnaei, von

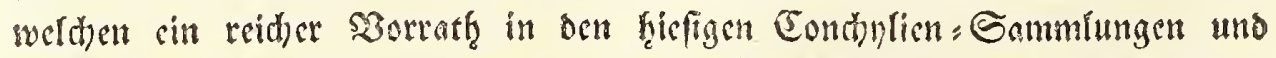

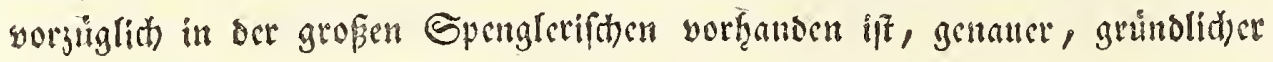

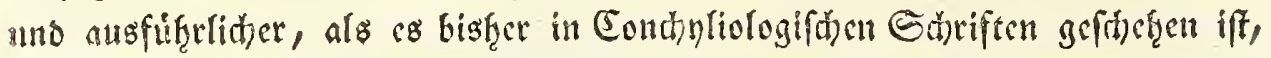

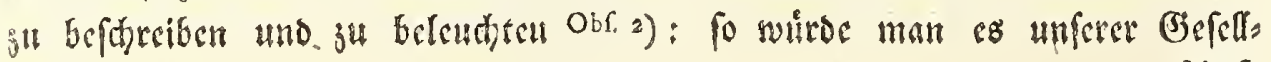
(t) aft

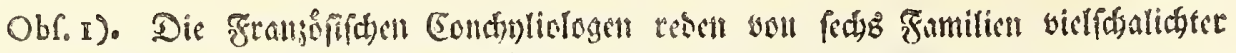
(Sondynlien. In ber erften ftel) bli Echini, ill ber andern bie Ofcabrions obet

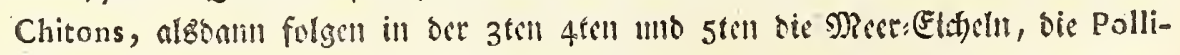

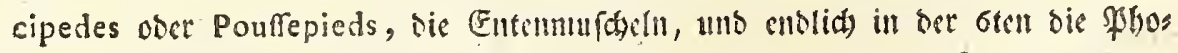
Intert. 2tarin ba bie Echini nidy fowwh ad teftacea follocen ad cruftacea ges boten, thto bic Pollicipedes nebfe ben Entenntufacill fidh füglith bey oen bala-

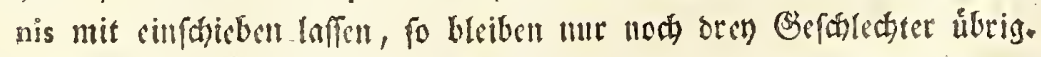

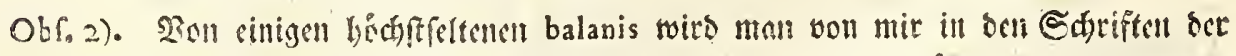

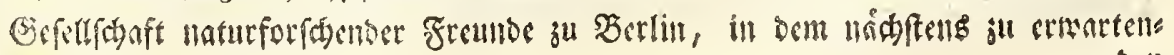




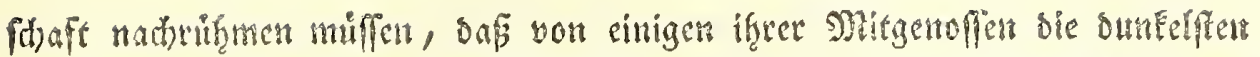

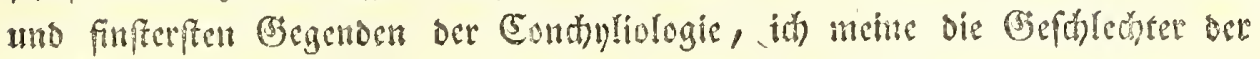

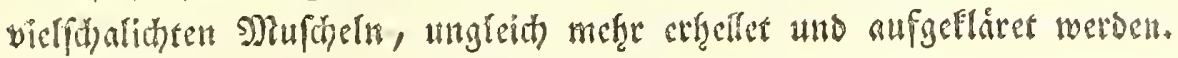

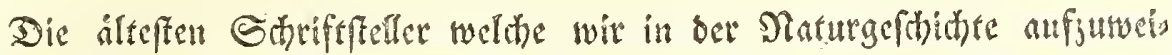

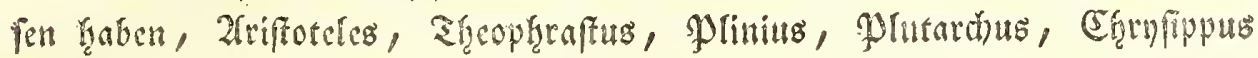

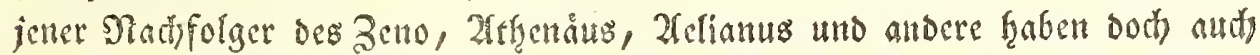
feime Sulbe in ifech fintertaffenen Echriften, daraus man es folgern Eornts

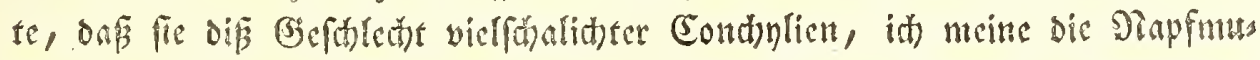

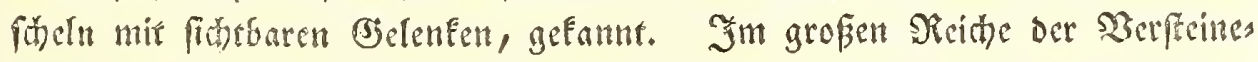

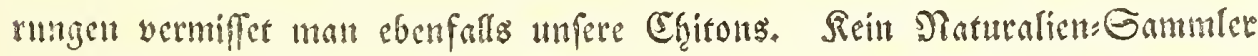

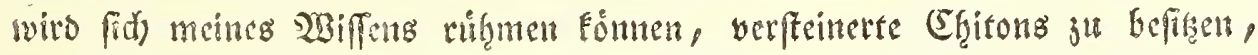
ja anth) vou den cinjelnen Gthedern, Belenten, Edhildern, Sthalen diefer fonderbaren Shiarare wird nidht leibte jemant wohlverfteinerte deutlide frags

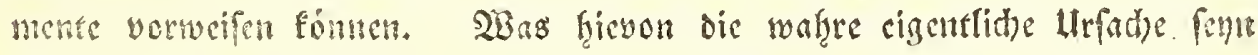

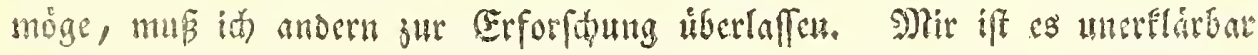
mo unerforpolitio.

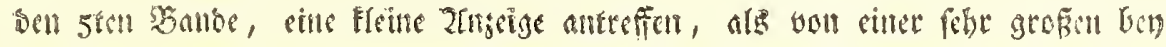

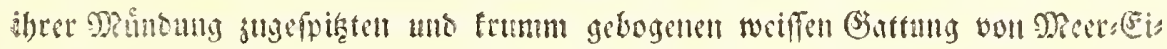

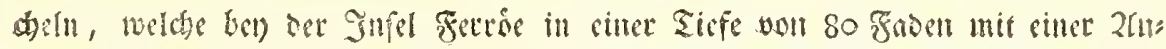

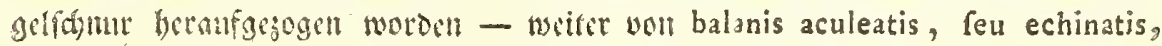

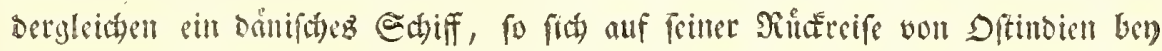

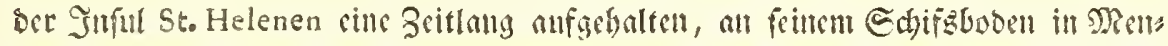

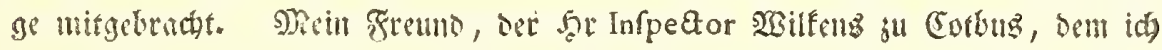

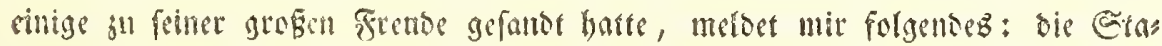

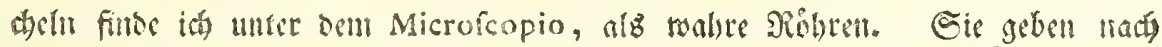

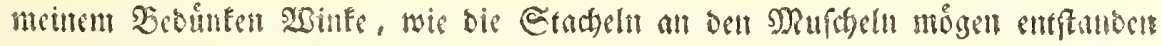

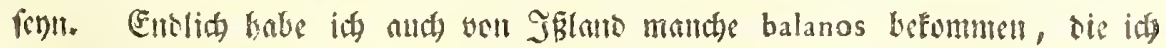

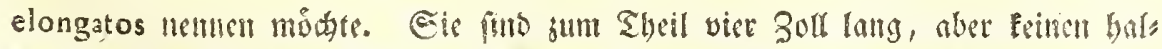

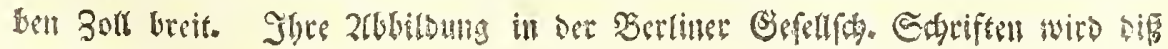
Sentlidyer matyen. 


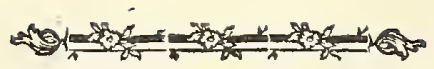

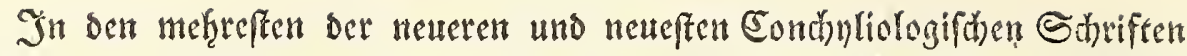

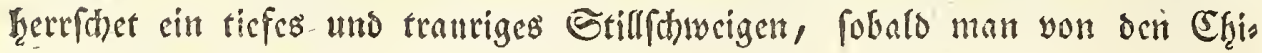
rons ctwas nåf̧eres und umpändlidscres wiffen, erfahren, uno erfragen

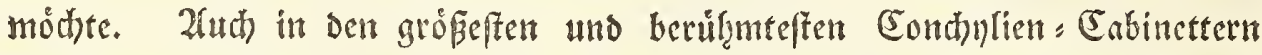
fino Ehitons grofe Seltenfeiten. So gar in Der wärflidben Sóniglichen Samms

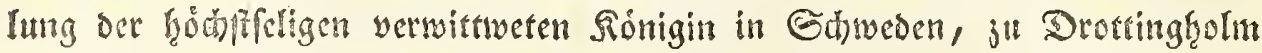

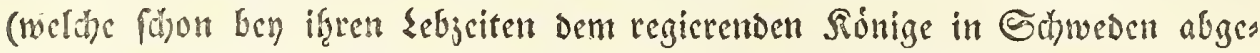
treten woroen) hat fith ju ber Beit, wie es Die Mcifterhano ocs Sinne in Dem alfen Condunliologen fo woht befannten vortreflid)en Mufeo Reginae Ludovicae Vlricae befartieben, mu ein cingiger Shiton, nemlith oer Chiton fquamofus befunden. Ilnd in Dem Saiferliden Cond)nlien= Cabinette zu SBien liegen nach Dem Indice, welben Der berúfemte Sorr Sofrath von Born de Teftaceis Mufei Caefarei herauggegeben, nur jwo Batttngen von Chitons, nemlid) Der Chiton fquamofus und der Chiton cinereus, weldber leastere nad Der 2ngabe nur orittlgalb sinien lang und eine Sinie breit fenn foll Obr.3).

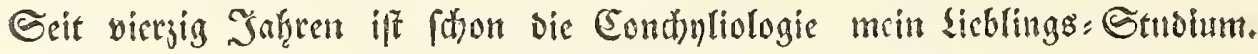

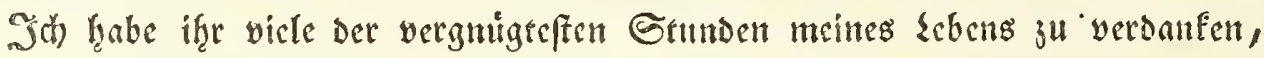
and fie hat midh jum offern jur efrecbictigften. Bchunderung meincs herrs

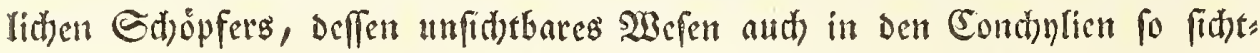

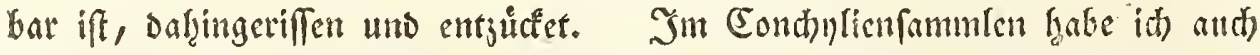

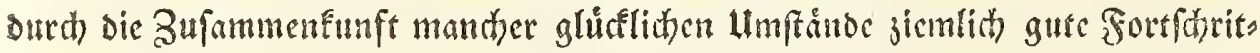
te gemat)t, aber mit Dem Gammlen Der Chitons hat ${ }^{2 B}$ mir nicmals rectit

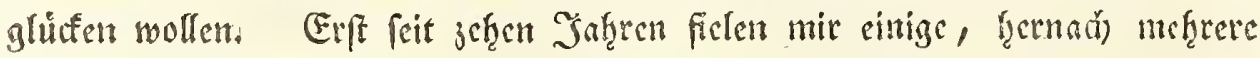

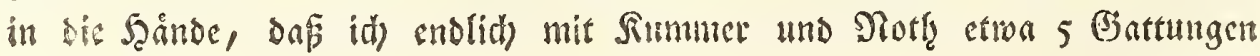
Derfers

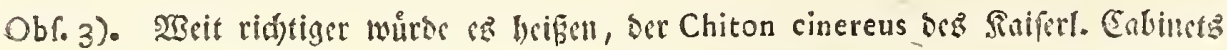

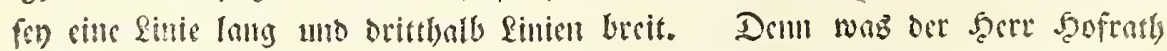

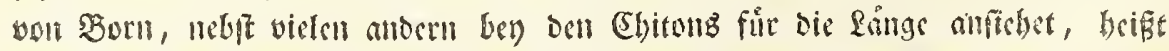

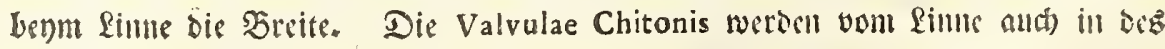
\$rof. Murray Teltaceologia alg longitudinaliter digeftae pag. 40. Fig. I. Les forieben mo Daben nody bie 2tmerting genacht: Valvularum hic enuneratus fitus Chitoni eft fpecialis. 


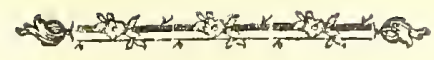

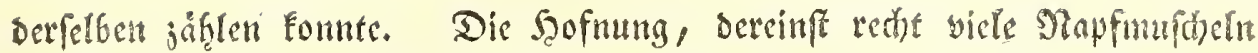

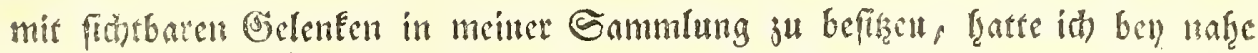

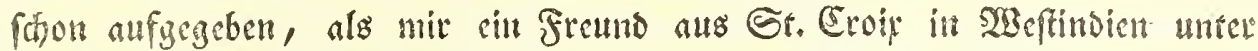
viclen anoern Eondinlien cinige Efritons wie zur Probe liberiande, ob ith

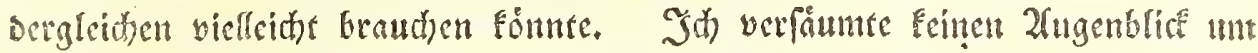

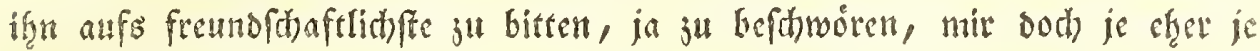

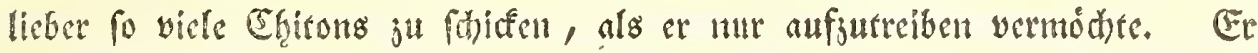

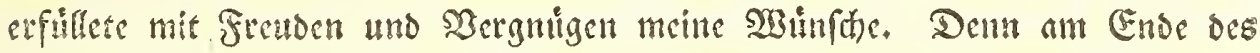

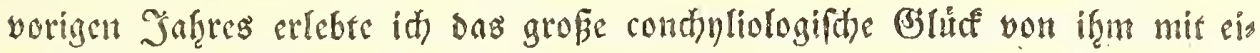

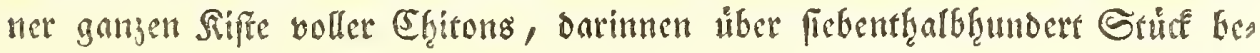
findich waren, befthent und ganj auperordentlict) erfreuet ju werden. Meit

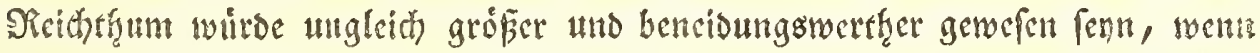

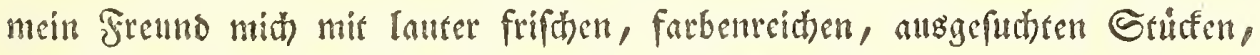

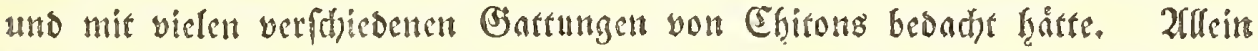
feine Dieger = Sclaven hattent gute und bofe, frifte und verdorbene, gefunt

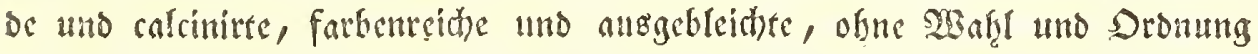

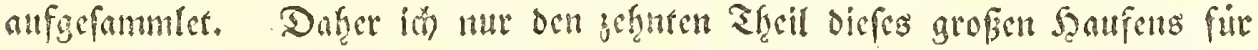

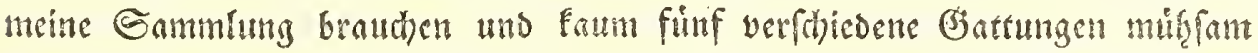
herausjuftuden vermothe. Soviel aber enfecter man aus bem biffgero gefings ten: Die Crgitong finto leidter ju finden als man es bisher geglaubet. Sic Iverden' auf forthen Stellen, wo fie cinferimifh find, ifere Eolonien angeleget

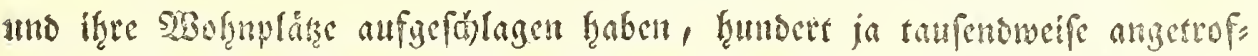

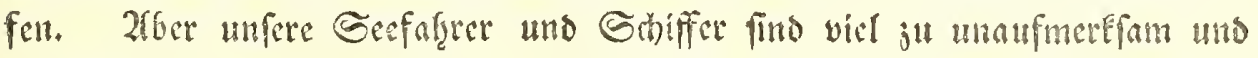

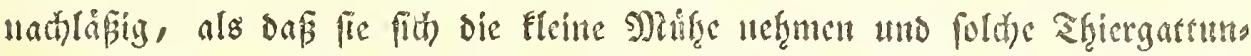

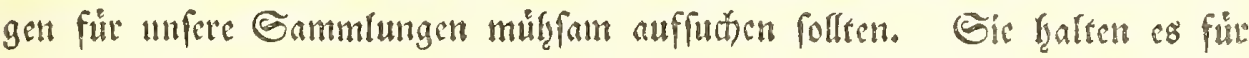
cine brodlofe Sumft und für cine citle, findifate, unnthe Sändelé und Spies

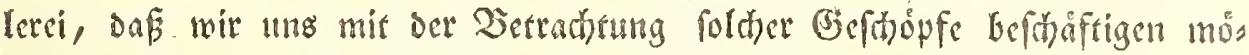

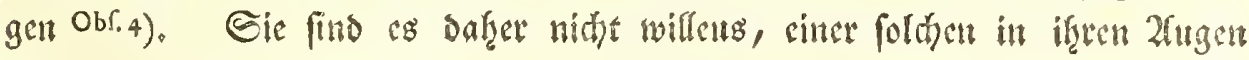
\$2 2

unto

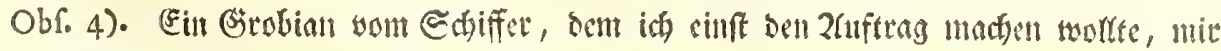

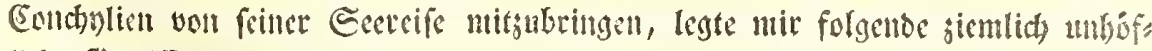

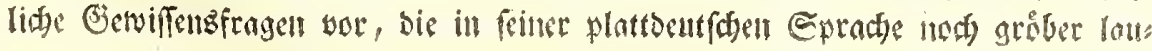




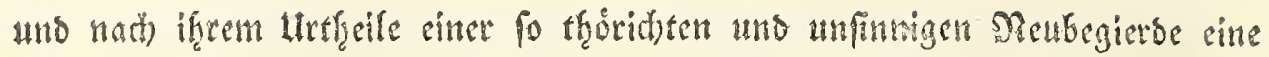

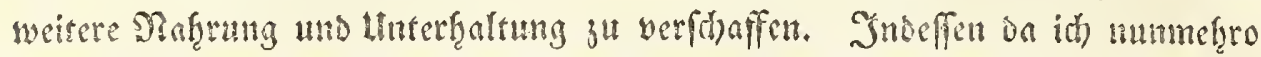

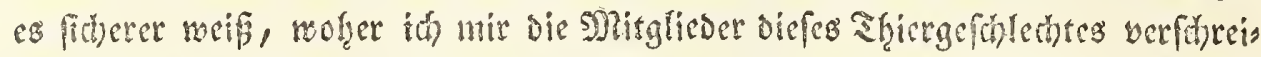
ben foll, fo habe it) unvergiglid alle giste 2 frifalten vorgetefget unt mit

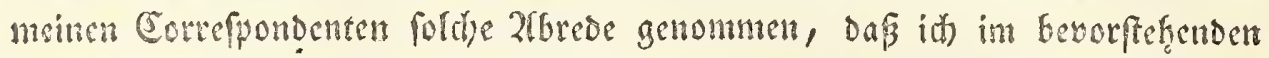

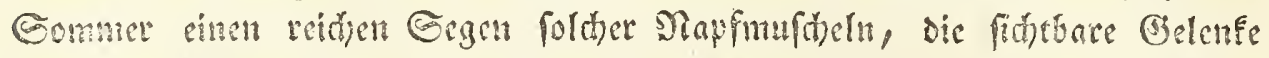

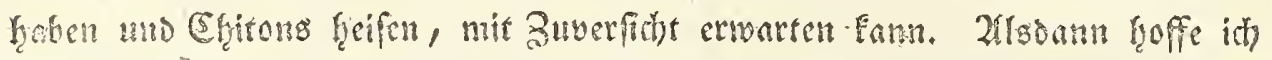

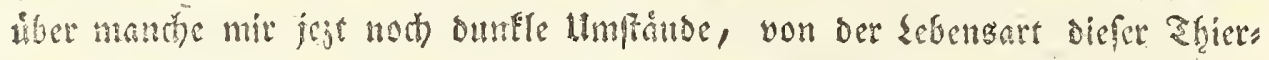
ant; und liber manthe mir voriegt not jweiferfafte Eigenfinafen serfelbsn,

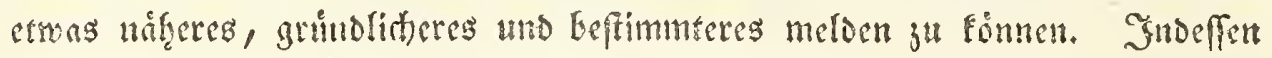
bitse the meine jetsigen vorlöufigen 2lumertingen, weldse idj bon diefent

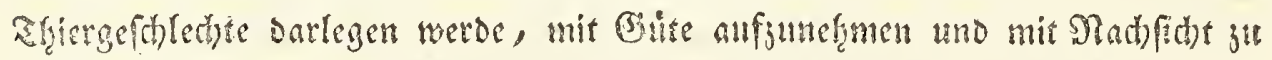

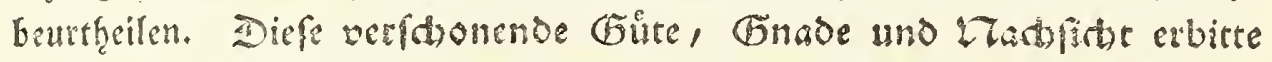
itb mir 5 ans befonders in tieffer Intertbanigeit von dem Durd) laubrigfen berzoge, meldin int beute bey diefer vollefung olls mei: nen 3uboere 34 verebren 0.06 Glint bobe.

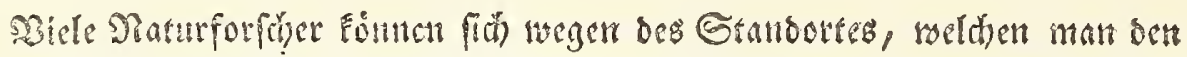

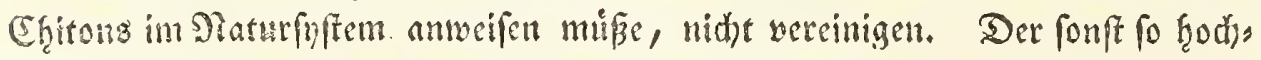

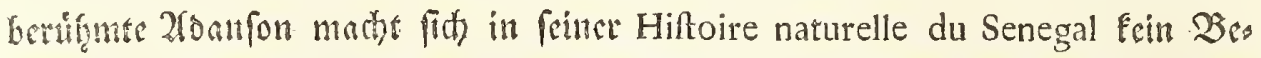

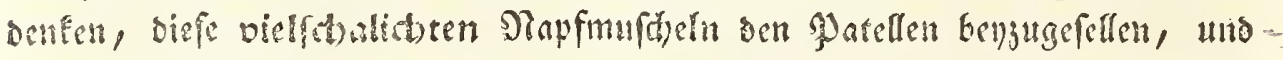

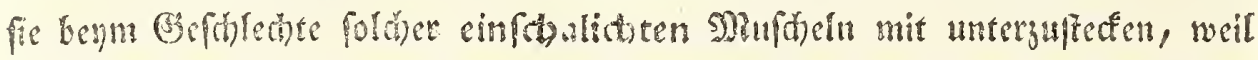

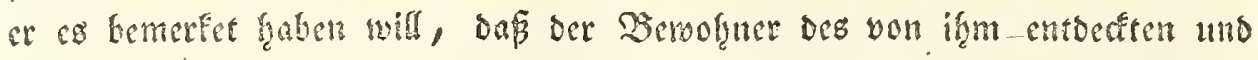
unter den Domen Kalfon, Lepas a coquille ecailleufe, bof friebenen Chitons

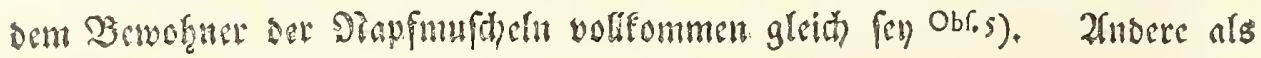
3. E.

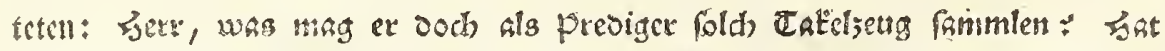

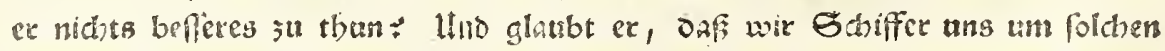

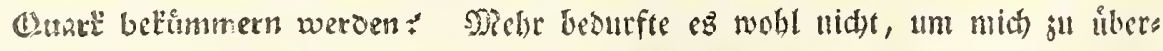

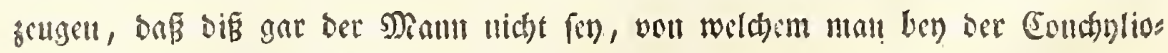
legie gesfe Beytrige erbalten werte.

Obf. 5). Adanion Hifto naturelle du Senegal pag.42. L'animal du Kalifon ne differe 


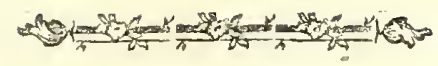

3. E. Mendes da Cofta in feinen Elements of Conchology troflen turb libers

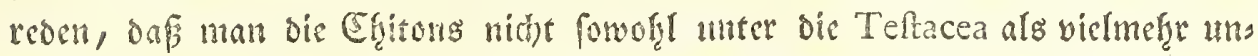

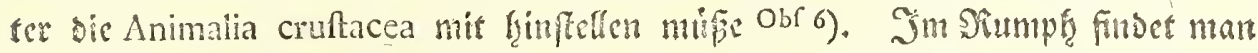

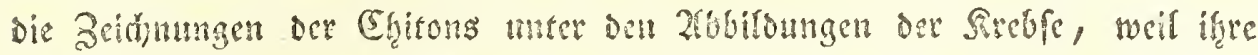

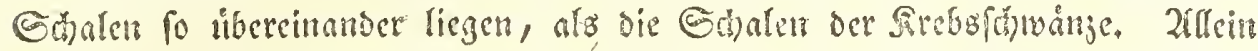
ba oer communis Doetor naturae curioforum oer grofse Lime, Deffen unferbs

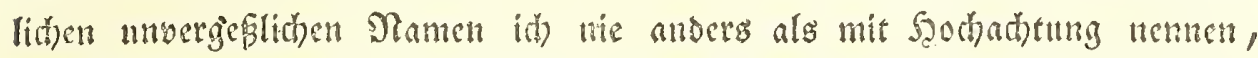

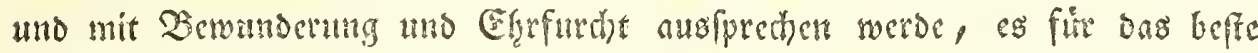

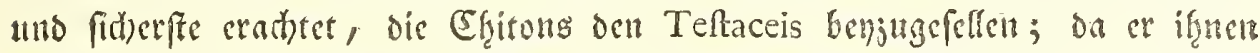

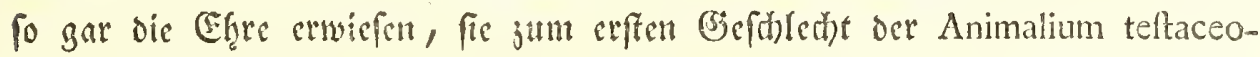

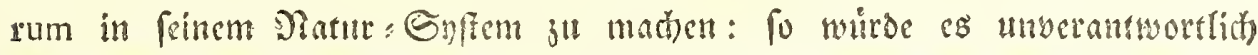

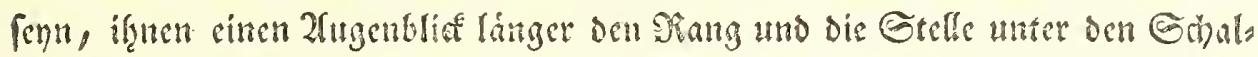
thicren abjuftreiten. Eie haben ia auti) whirflid) domum feu teftam calca-

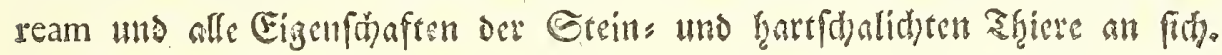

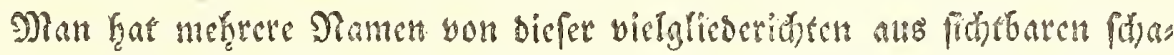

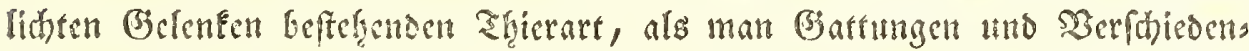

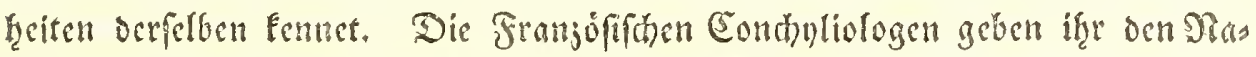
men, Lepas multivalve a huit cotes. La Nacelle de mer. La Chenilie de mer. $\mathfrak{B}_{3}$

$\Leftrightarrow$ Le

differe pas moins que fa conuille de toutes les autres efpeces de Lepas que j’ai

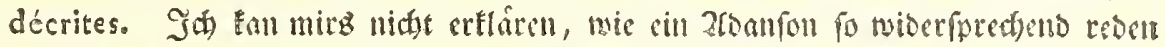

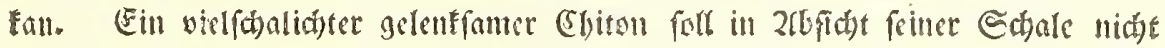

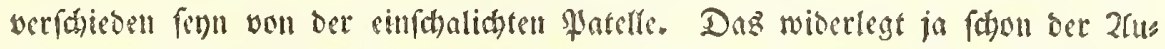

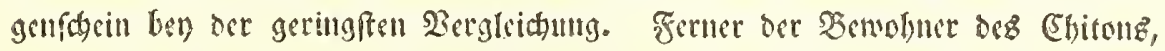

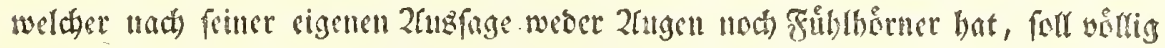

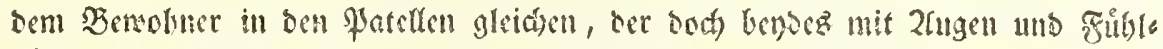

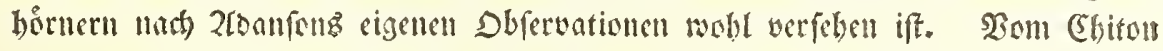
behauptet er es: On ne voit pas la moindre apparence des cornes ni des yeux. Obf. 6). Mendes da Cofta Elements of Conchology pag. 280. There is another fet of marine animals called Oscabiorns, which though their covering is like Shells, yet $i$ cannot agree to rank them as tefacea, for i thiik liks the Eshini, they are genera of cruftaceous animals, 
Le Cloporte ou la Chalouppe de mer. La Punaife de mer. Cimex marina. Zin

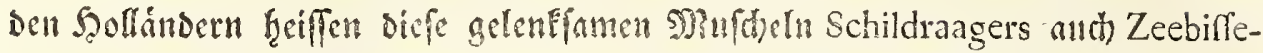

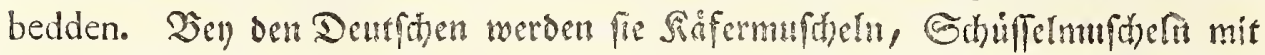

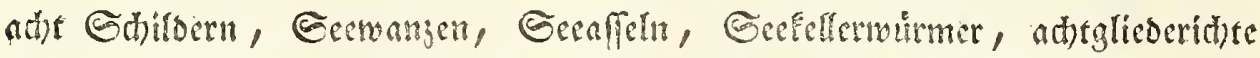
Dhofmufbeln genanut. Die liete Einfalt nentet fie Ed)!angenfronen, weil

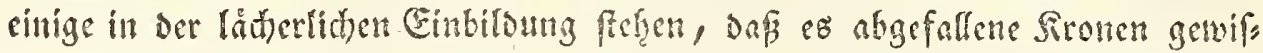

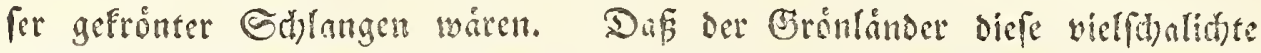
Mufdel s Battung mit den Dlanen Terkeingak uno Triftrendingur beneme, neloet Fabricius in feiter Fauna Groenlandica pag. 420.

Bom Sinne werden wie gelenffamen Dapfmufoln Ehitons genannt. Das Wort Xitwy bebeutet bey Den Griethen Gald eine folthe Gattung von

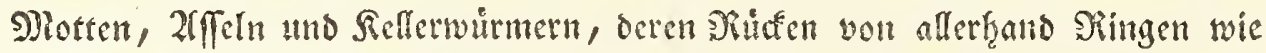

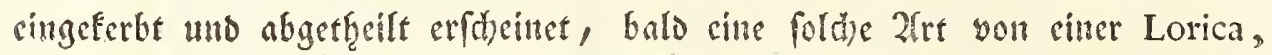
von cinem Panjer, ber aub lauter Singen uno 2übtheifungen befefer Obr. 7 ).

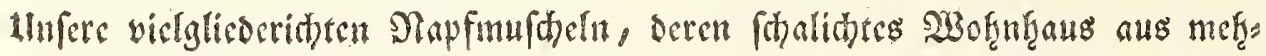

reten

Obf. 7). Pennants Zool. Brite tom.4. pag.6r. The name Chiton taken from - zraw Lorica a coat of mail. vo Born Teftacea Muf. Caef. pag. 3. Teftas ovae to-oblongas compofitas valvis fex, feptem aut odo, fibi invicem imbricatim adpofitis hoc genere comprehendit Cl. Linnaeus, et nomine, ob fimilitudinem quandam cum Lorica, a graeco verbo жzan mutuato teftaceorum Claffi primus

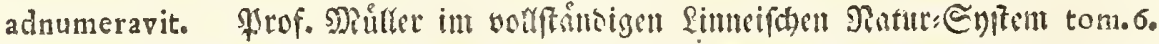

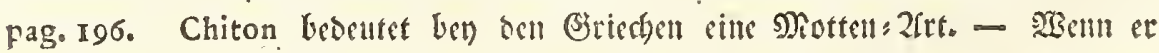

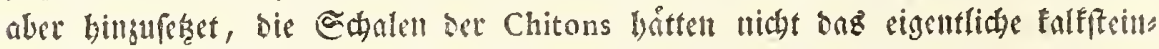
arfige Beftantroefen, - weldyes man an ben ibrigen Condfylien finte: fo bienem

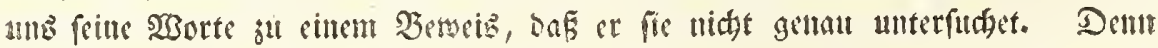

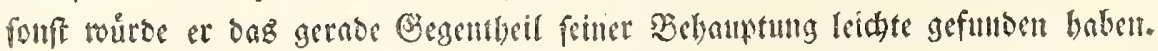

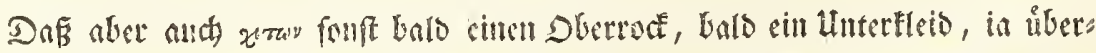

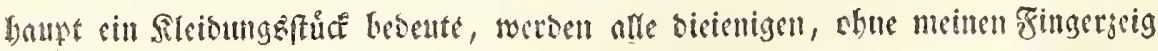

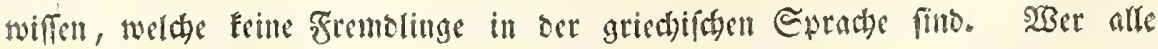

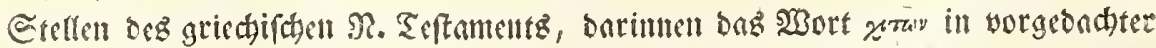

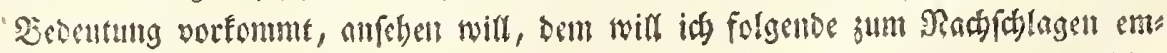




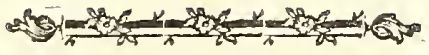

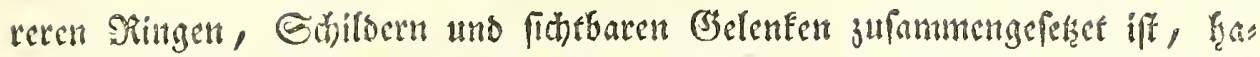

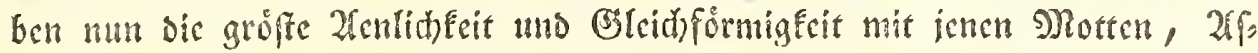

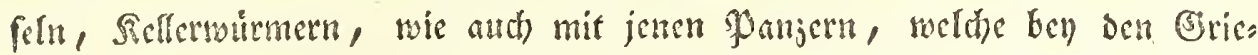

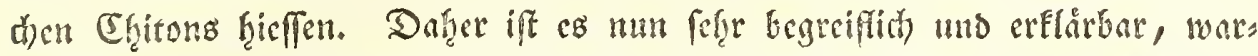

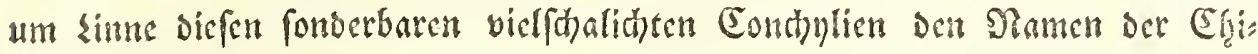
tons ertheilet.

Bey Den Englänoen hat juerft Der befannte gelefrete 2pothecter ju Souts ben, Sacob Petiver, Den Damen Ofabrion in feinem Gazophylacio naturae et artis Vol.I. tab.I. fig. 3. von biefer SGicrart gebrauthet und anfgebradbt, weil er vermuthlith von bem Snfecte, welthes bey den Sfflendern Oskabiorn f̧eifft, etwas gef̧oret, $\mathfrak{c B}$ atth woht unter diefen פlamen befommen, uno in

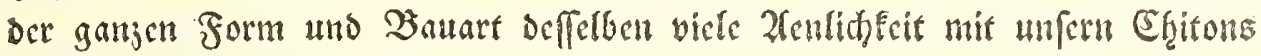
entbedet und bemerket hat Obros).

Dic

pioblen bilben. Matth. V, 40, X, 10. Marc.VI, 9. XIV, 63. Luc.III, Ir. VI, 29. IX, 3. Iohan. XIX, 23. Ador. IX, 39. Epift. Iud. v. 23. Slmftreitig hat zozaly

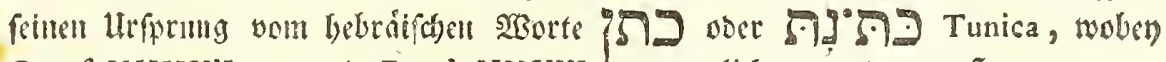
Genef, XXXVII, 32. unt Exod. XXVIII, 4. verglichen werdell mus.

Obf. 8). Petiver Gazophyl. Nat. et Artis vol. I. tab. I. fig.3. Ofcabrion Carolinianus perelegans fquamis bifariam variegatus. Er meloet Daben $\|$ do folgen Deg: This elegant Animal was given me by my honoured Friend Dr Martin

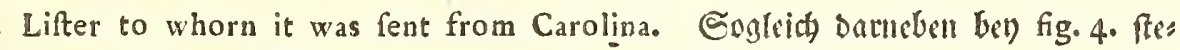

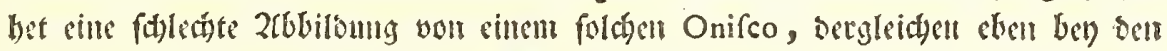

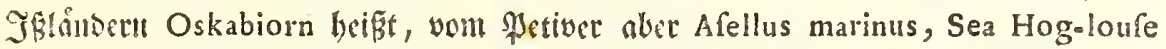
genamt mo alg e nigro luteoque ftriatus beffrieben wirb. \$etivers Chiton Carolinianus ift oer eigentlitbe Chiton fquamolus Linnaei, Er batte nlfo im Rins

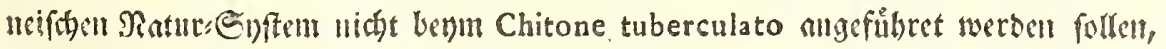

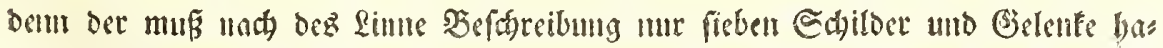

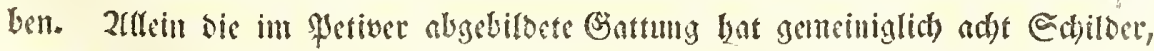

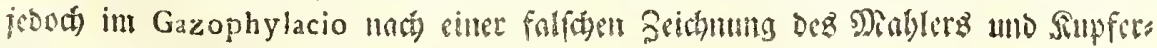
frederb gar neun Edtilber. 


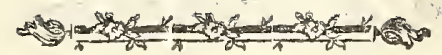

- Die Frangofinen Contimliologen haben befen von Petivet angegebenen Delamen Oscabrion algemein firc afle Chitons aboptiret, mo fie inggefamt Osca-

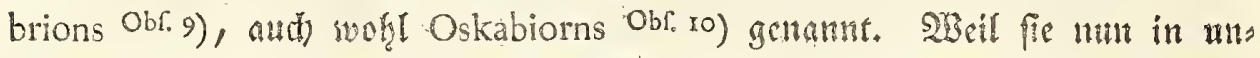

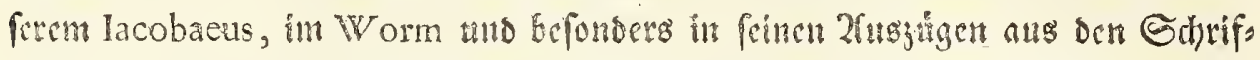

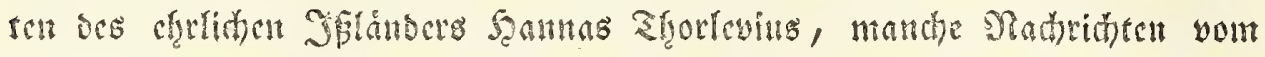
wahect Jifländfün Oskabiorn, ober ath Oenskebiön angetroffen, fo has

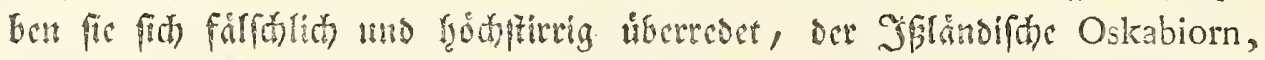

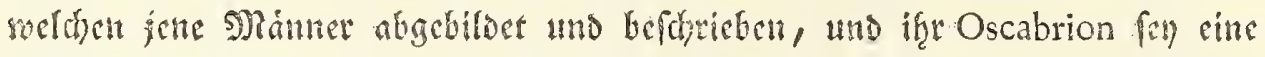

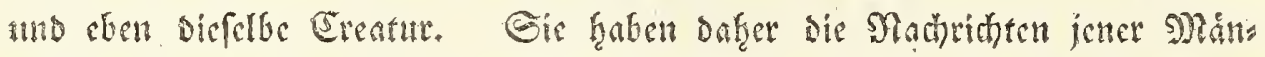

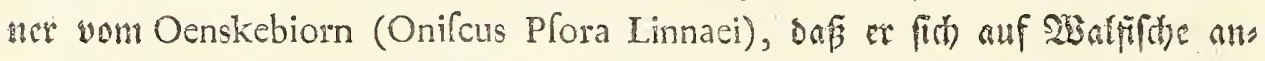

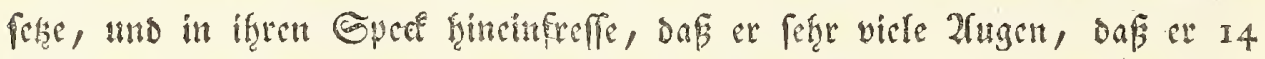

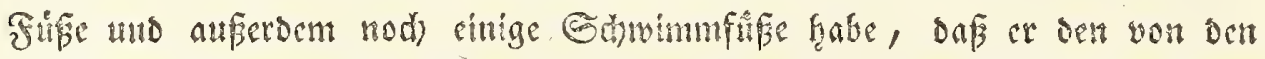

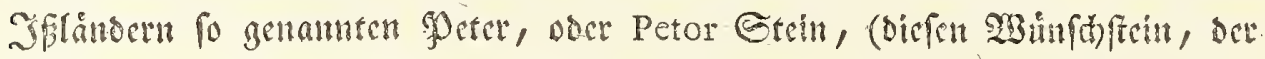

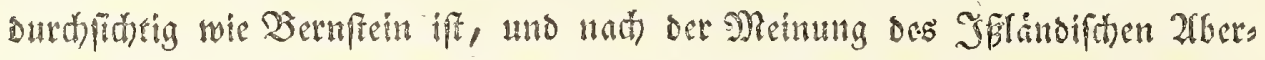

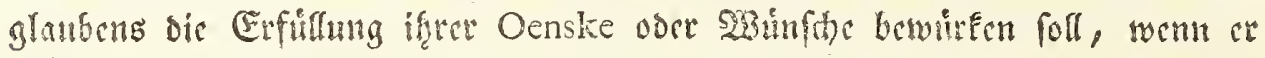

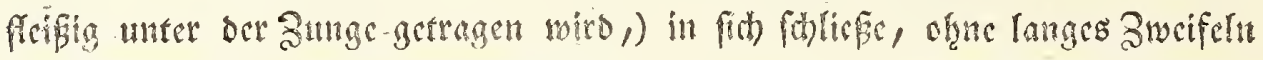

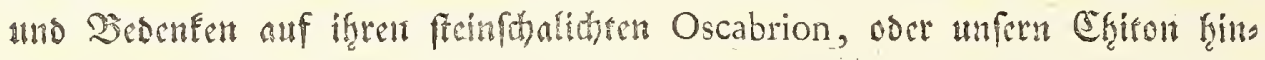

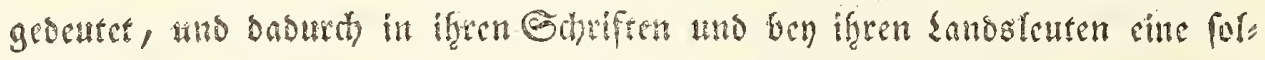

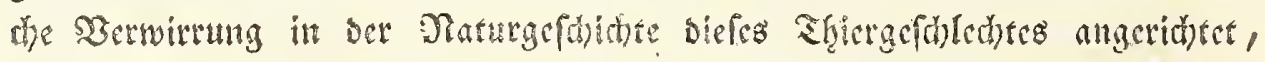

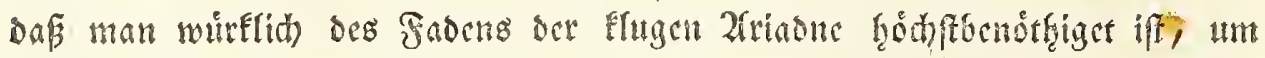
fid ans diefen Iaburintfeifonen Jrrgången wiescrum fecraus ju finden. Es

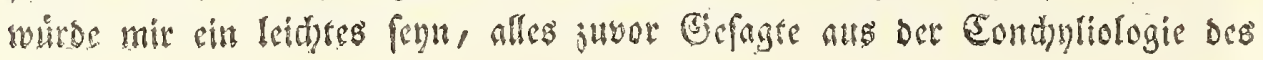

Dar-

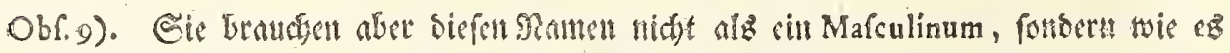

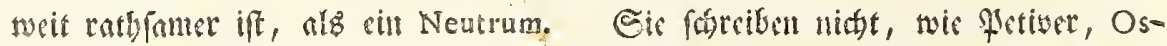
cabrion Carolinianus, fontert Oscabrion Carolinum uns eine andere Gattung,

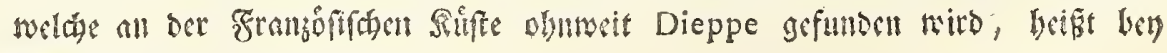
ihnen Oscabrion Gallicum.

Obf. Io). vide Favart d'Herbigny Diaionaire d'Hiftoire naturelle tom. 3 . pag. 56. Oscabrion on Oscabiorn, ou Lepas multivalve a huit côtes.

It. Mendes da Cofta Elements of Conchology pag. 280. There is anothe: fet of marine animals called Oscabiornse 


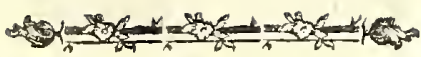

Dargenville, wie audi) alts feiwer Zoomorphofe des Coquillages, fertute ants Dem Dictionaire raifonné univerfel bes Bomare uno ans dem Dictionaire d'Hiftoire naturelle des Favart d'Herbigny uno aus anderen framjoffichent

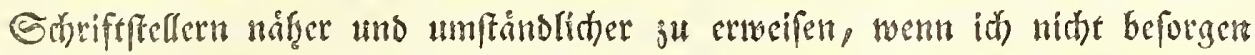

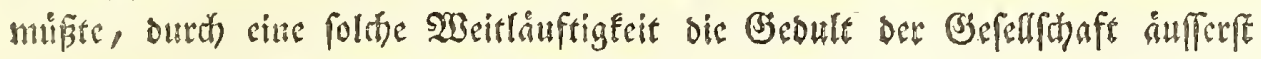

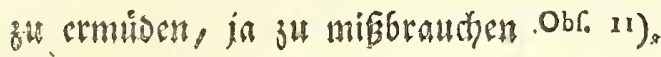

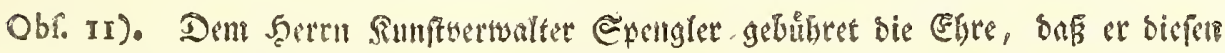

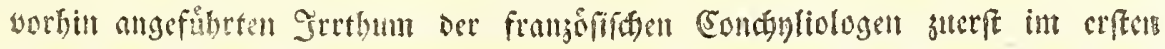

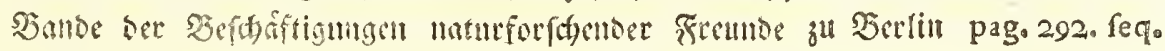

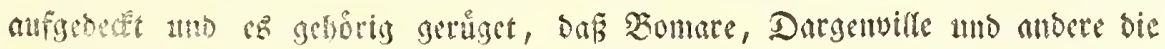

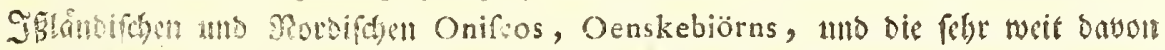

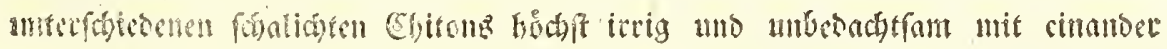

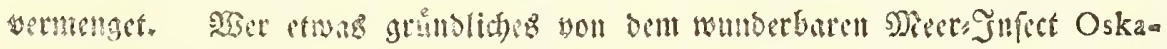

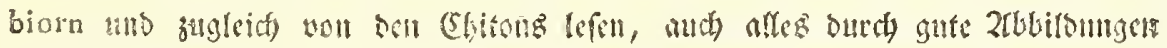

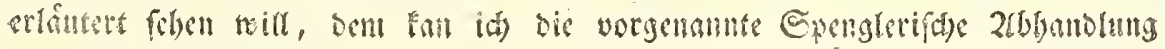
nitbe genng empfobien.

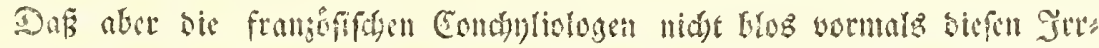

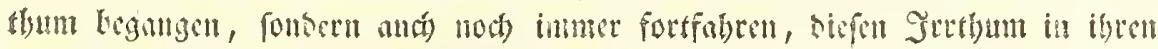

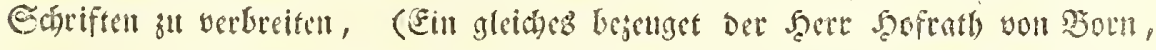

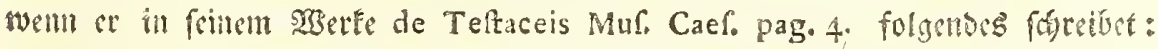
Cum diverfis Onifei fpeciebus in hune usque diem confunditur) meroe in mif rinigen Cteften beg Favart d'Herbigny d'Hiftoire naturelle qui concerne les

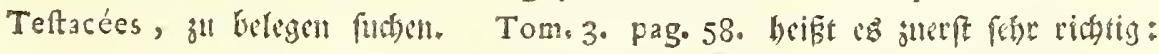
$\mathbb{L}^{\prime}$ oscabrion n'a point de cornes, point $d^{\text {' } y e u x, ~ p o i n t ~ d e ~ p a t t e s ; ~ a u ~ m o i n s ~}$ il n'en paroit aucune. Il rampe fur les rochers comme le lepas. - Hadenus bene - 2rber mun folget die Eodition beg Chitons und Oskabiorns, Les ątes de Copenhague ainfi que la collection acadenique font mention d'un coquillage appellé Oscabrion qui fe trouve dans ia mer d'Islande. L'Cs. cabrion ou l'Oscabiorn de l'Islande eft mentionné par Iacobaeus - M. Wormius notre compatriote (watum er unfern banifan Wormius fo nen nen fomme, begreife idj) nicht) nous a donné la defcription de l'Ofcabiorn, a sais comme on n'eft cntré dans ancun détail fur fes yeux, qui par leur fru= aure finguliere font l'une des parties les plus curieufes de fon corps l'au= 
23ey ben Dlamen Der Chitons mufe foron fo bieles beriftiget werben,

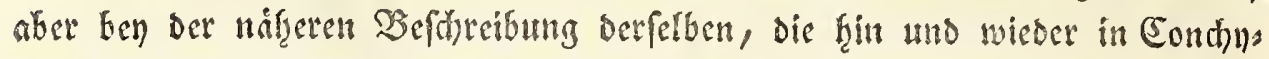

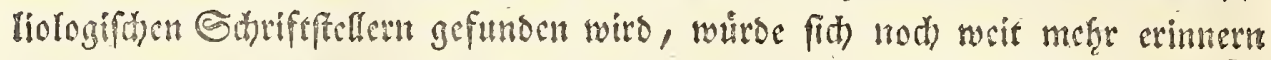
Ino anmerten laffen, wenn wir ums lange onmit auffalten mód)ten. Det

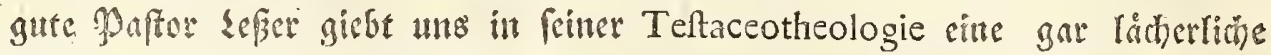

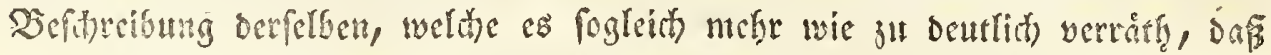

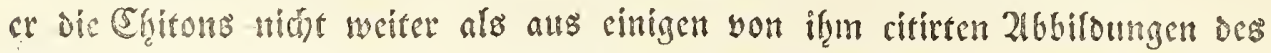
Seba uno gyetivers getant. Sollen wir es vermuthen, er nemnet die Chis fons blof langlichte vielfitalidte Nutsen, welde beffer angefeben als bes fibrieben weroen Eónnten. Er giebr ifuch aud nur fieben Gislente oder Edjilder.

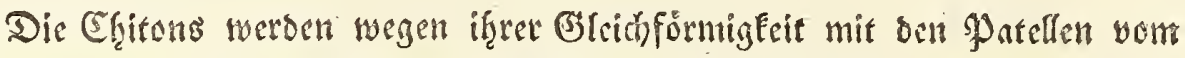
Elonne in friter Hiftoria Iamaicae beftrieben als Patellae oblongae articu-

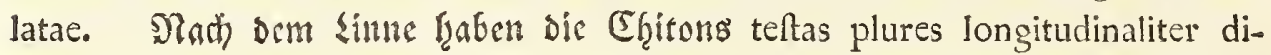

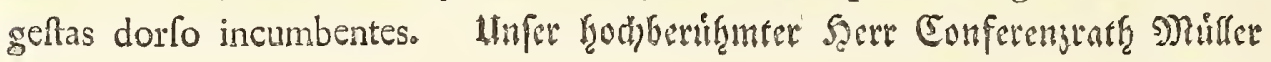
rectinet,

teur a jugé a propos d' en parler. Il en rapporte $d^{9}$ abord ce qu'en a dit un auteur d'Islande même; c'eft Hannas Thorlevius homme fincere, très hae bile et fort verfé dans l'hiftoire: voici fes propres termes. Le nom de l'os. cabiorn doit fon origine à la fuperfition, il eft compofé de deux mots Biorn, Ourfin, et Oskar voeux on Couhait. L'animal a été ainfi nonmé parce que felon l'idée populaire, quiconque peut avaler la pierre, qui eft cachée dans fon corps, obtient facilement l'accomplifiement de tous fes fouhaits. La pierre de l'oscabiorn fe nomme en Islande Petersftein, pierre de St. Pierre.

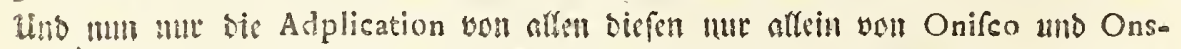

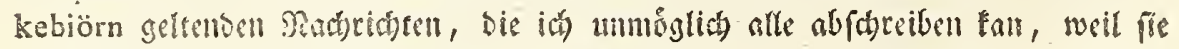
gange Ceiten eimulmen, auf mifere Ebitons. - Cette defcription de Thorle. vius eft affez exaate. L'oscabionn eft du genre de teftacées ullio pag. 62. Les autres tefracées ont des yeux qui débordent un peu au dehors de la tête, et qui par cette fituation peuvent fe tourner aifément fur tous les objets qui font a leur portér: mais il en eft dedommagé par la multitude des fes yeux. 


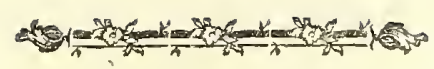

refontet fie in feintm Prodromo Zoologiae Danicae pag. XXXI ad teftacea multivalvia. Ex fagt fie ḩătten valvulas dorfales et tentacula nulla.

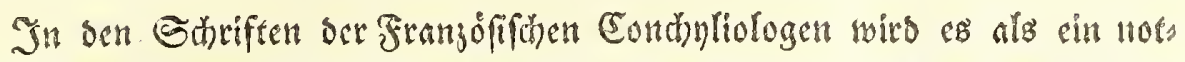
wendiges und wefentlithes thuterfhcioungs, Menfinal ber EGhitons angegeben,

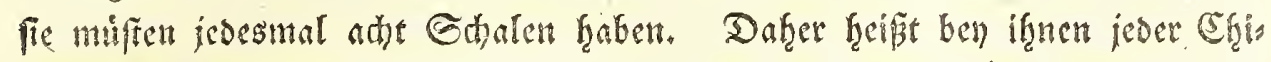
ton Lepas multivalve a huit cotes. Sa coquille fontreibe Dargenvilfe in fair ner Zoomorphofe des Coquillages, eff compofée de huit pieces entierement detachées et jointes à la chair de l'animal par de petits crans qui s'emboi-

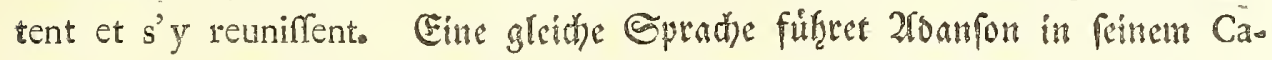
talogue raifonné tom. I. pag.392. Nous ne pouvons nous difpenfer de rapporter les ofcabrions aux Multivalves. Elles ont la forme d'un demiovoïde, et font compofées de huit écailles courbes, pofées en recouvrement les unes fur les autres de devant an arriere, relevées toutes dans le milieu d'une petite côte plus ou moins aiguë, et enclavées vers le bas dans une membrane flexible, écailleufe et chagrinée dans fon contour. Im Di.

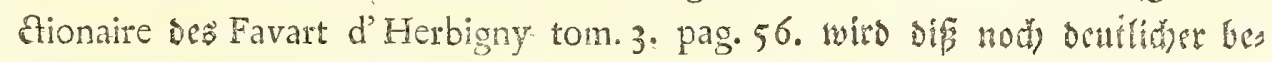

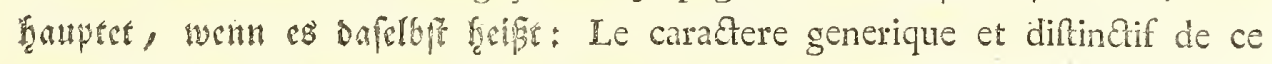
coquillage eft d' avoir une figure ovale, allongée et arrondie aux deux extrémités, d'être compofé de huit écailles ou huit pieces en maniere de côtes, qui fe recouvrent et fe.meuvent les unes fur les autres comme celles de la

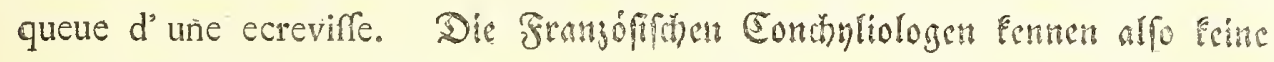

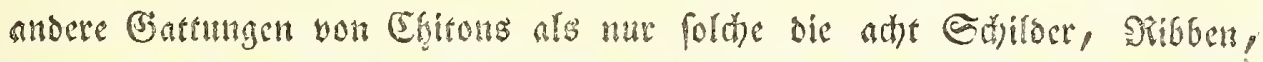

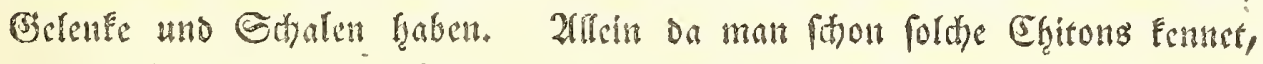

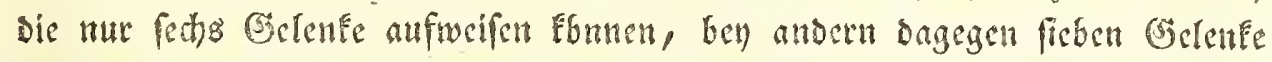

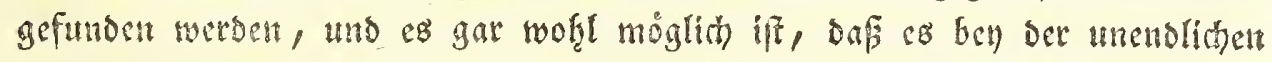

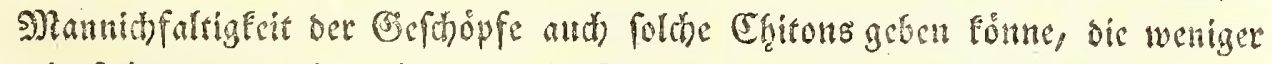

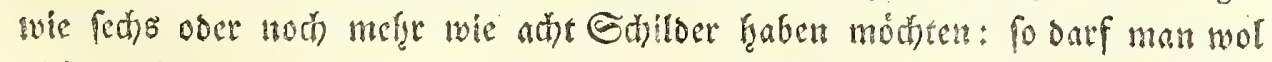

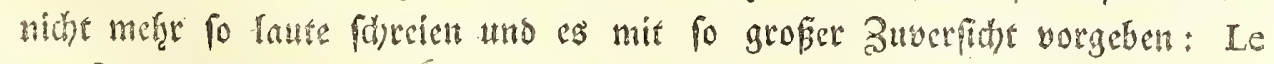
caractere difinctif de cé coquillage eft d'étre compofé de huit ecailles.

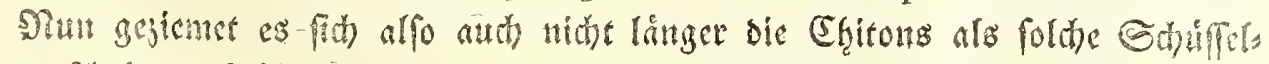

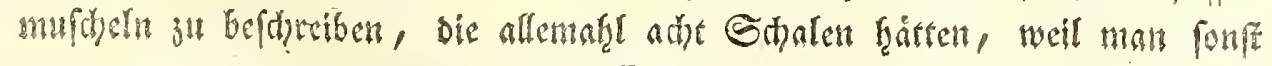


mit feinen Definitionen in eben ben Fefflex verfallen wirto, in welben see ehemalige um die Mlaturgeftichte unfterblith verdicnte Secretair ber Stode

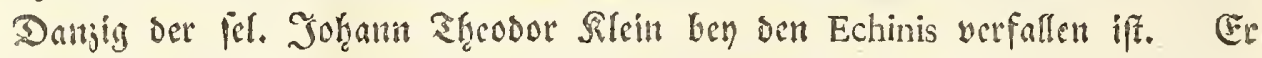
fratte $\mathfrak{c}$ in feiter naturali difpofitione echinodermatum als cin juverfáfíges

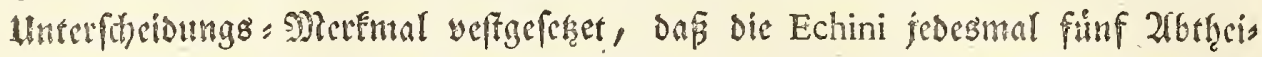

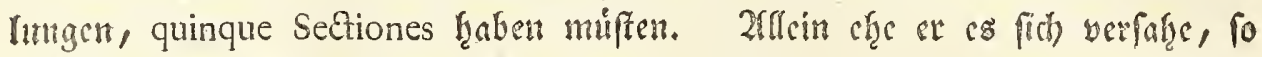
Ḧberfantete ifgm ser vornchme Banquier ju kubef, oer fet. Tesdorpf cin pare

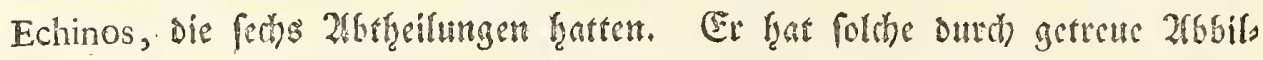
Dungen und 3eidnungen im 2ten Bande oer Berfutche und 26handungen, oer maturforftemoen Gefelfhaft ju Danjig pag. 292. feq. tab. 5. fig. 4. 15.

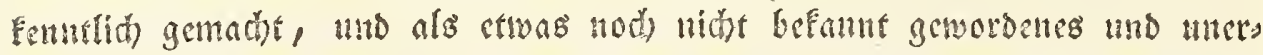

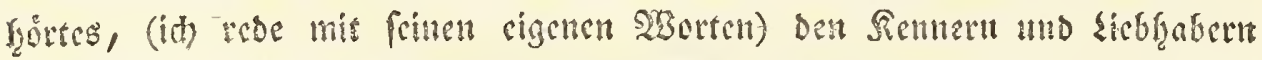

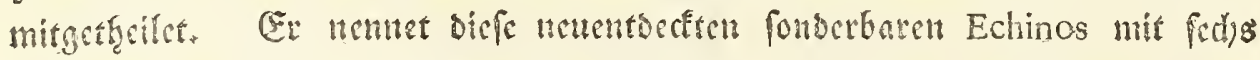

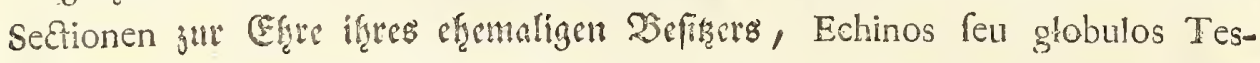

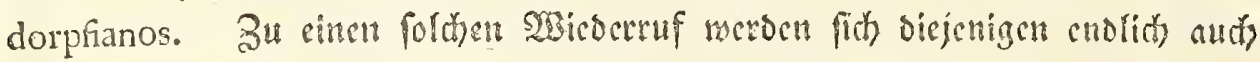
bequemen miffen, weldye voriest nod) fither fortfafyen, es orcifte in dic Welt

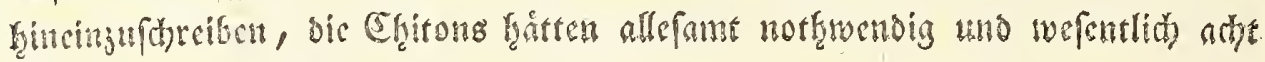

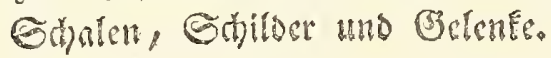

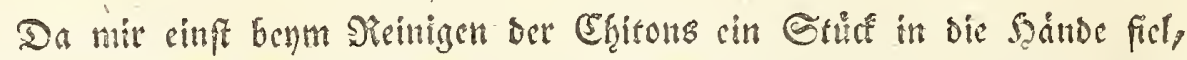

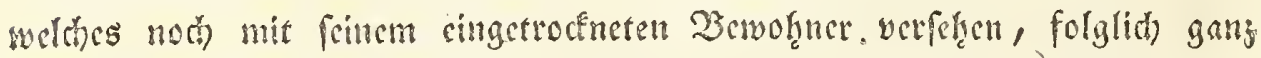

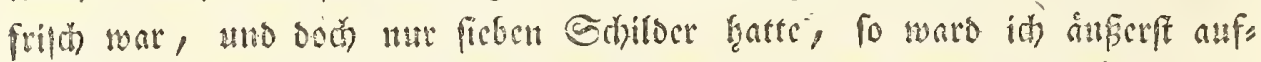

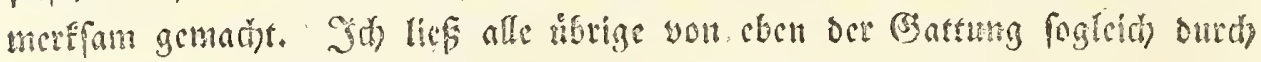

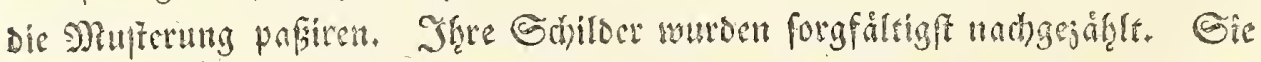

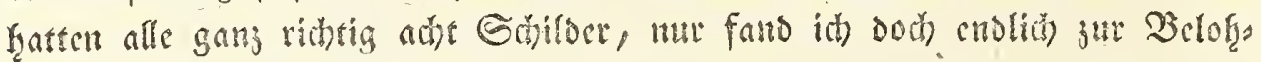

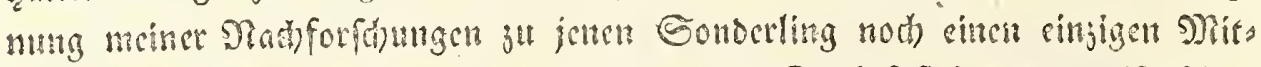

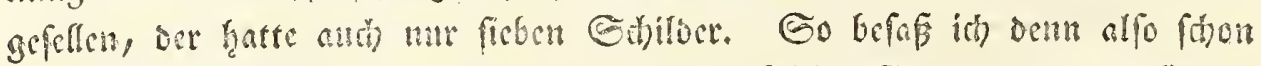

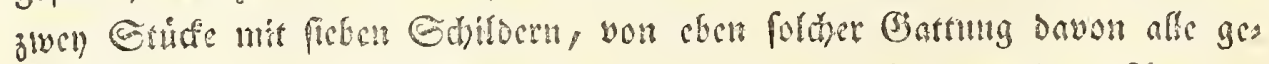

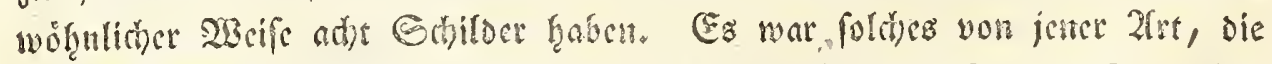
bey mir Chiton variegatus faber Ind. occid. heipt, uno fig. 3. anf ocr Sius

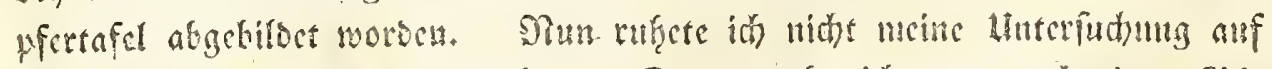

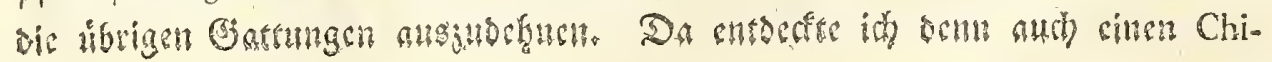




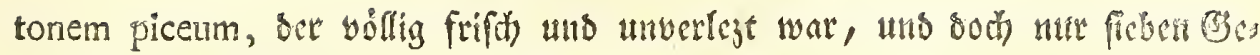

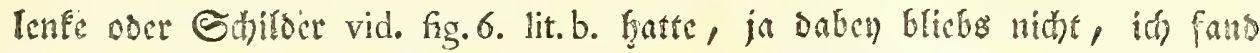

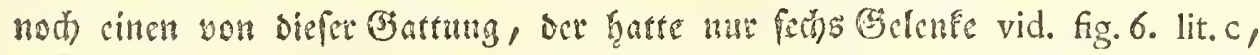

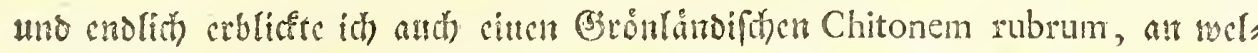

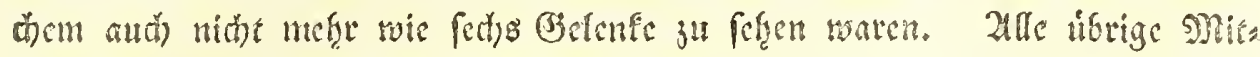

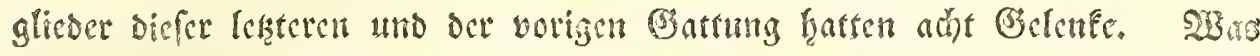

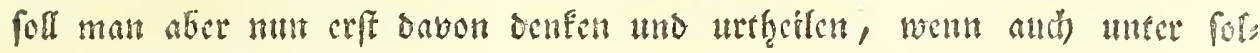

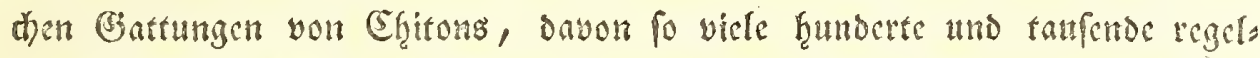

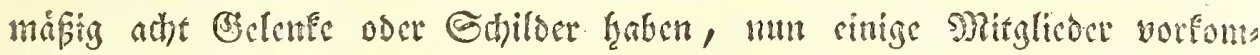

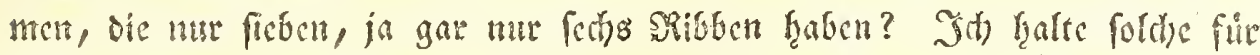

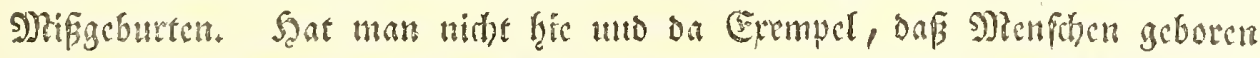

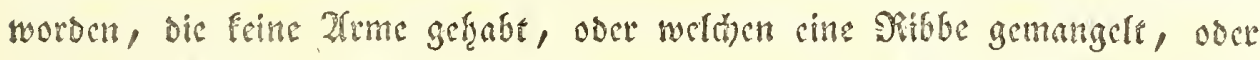

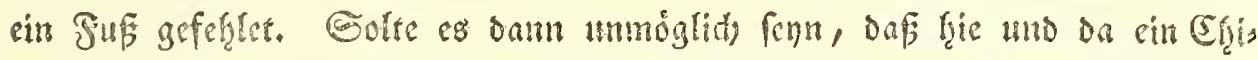

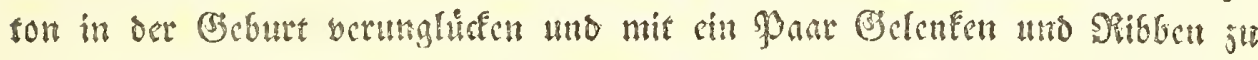

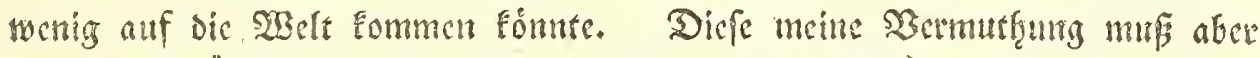

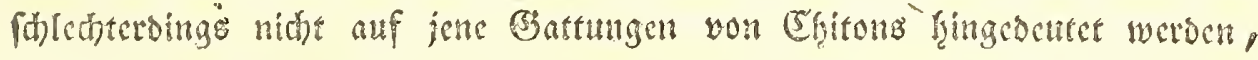

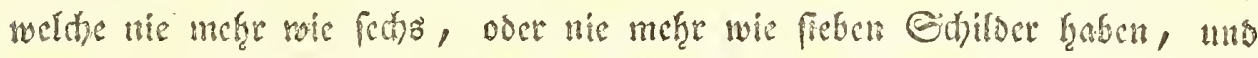

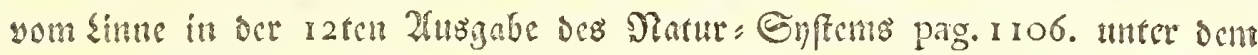
Namen Chiton hifpidus uno tuberculatus, uno vom Pennant in finer Zool. Britannica tom. 4. pag. 60. untee Dem Damen Chiton crinitus feffiricben

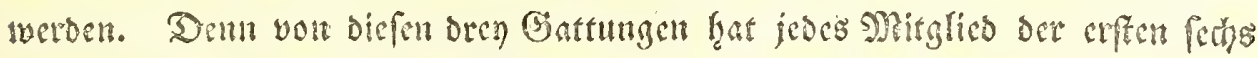
und won ben andern beyben Battungen jeoes smitglico fieben Ebilloer.

Es find ibrigens sie (Efitons Conchae multivalves parafiticae, bie fith

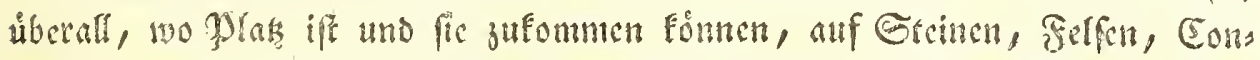

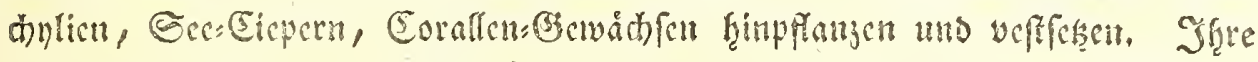

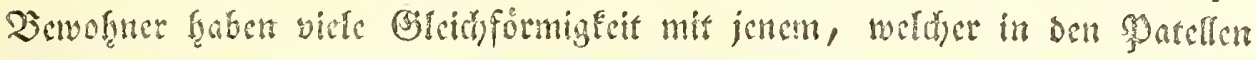

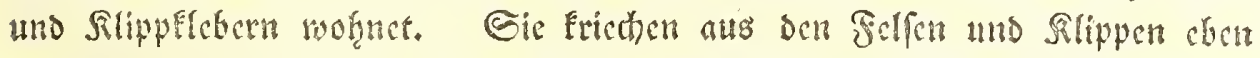

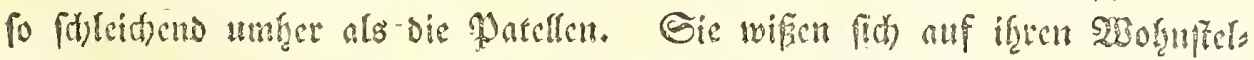

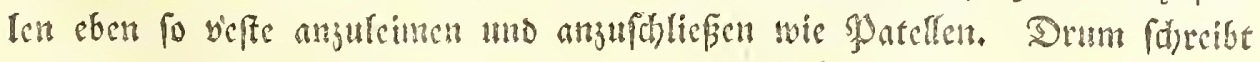

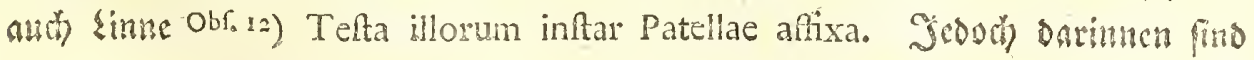
(s) 3

Obfo 22, L Limnei Syft, Nat, Edit, I2, pag, ILO\%, no. $\%$ 


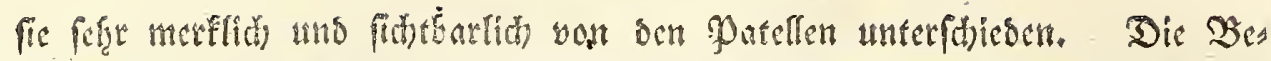

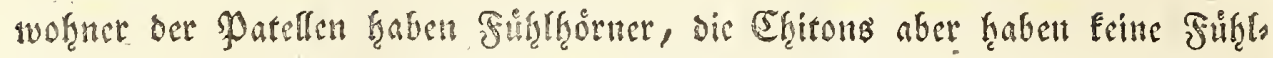

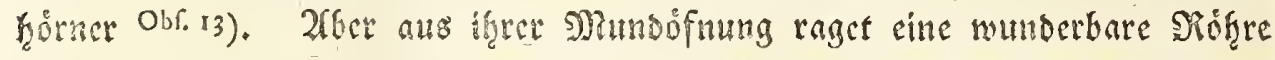

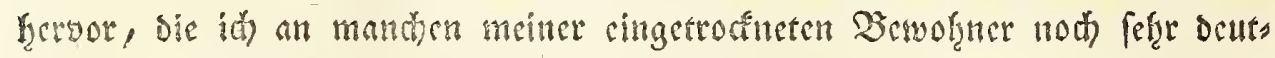

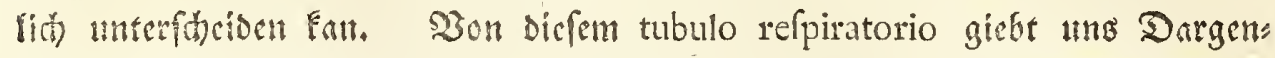
viffe in feimer Zoomorphofe des Coquillages thatfolgente lefenswüroige Na(h) vidift $\mathrm{Obr} \cdot \mathrm{x}$ ) ). Sa tête faite en croiffant eft arrondie et eft percée d'un trou ovale par lequel fort un tube fermé par le bout de deux demi-globes. Quand la partie de fa tête n' eft pas appuyée il fait agir cette efpece de tube comme par refpiration et il paroit et difparoit presque au même tems. Ce mouvement pectoral a été obfervé à la loupe plus d'une

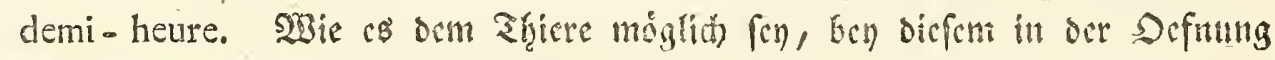

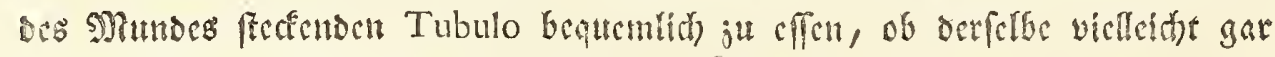

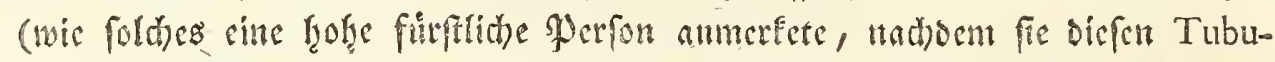

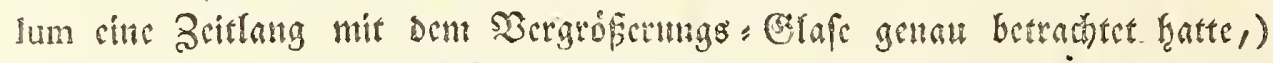

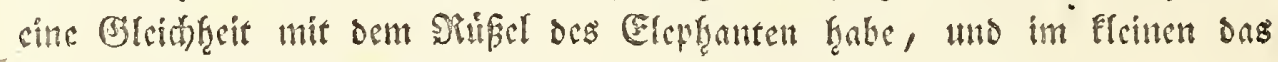

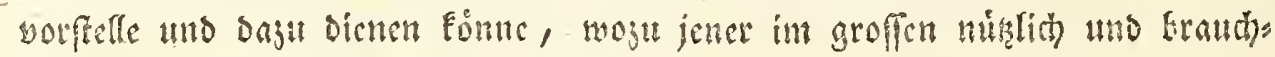

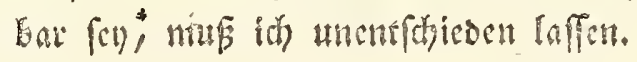

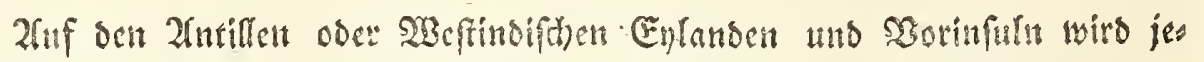

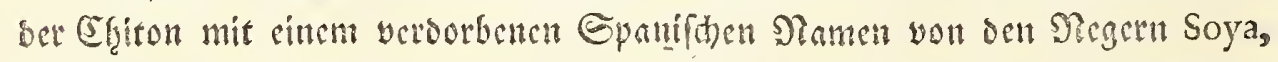

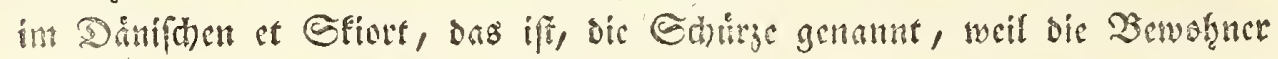

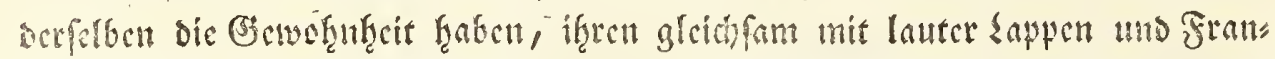

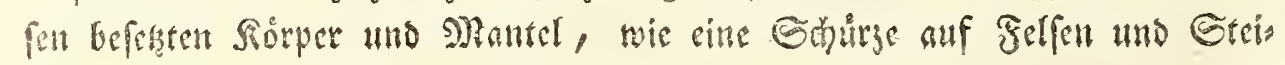
nen arsjubreiten. -

Mein

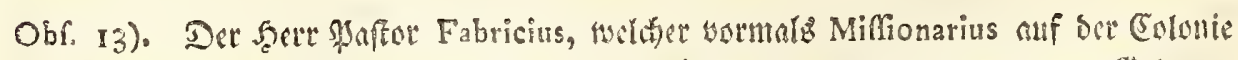

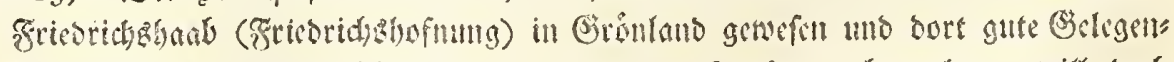

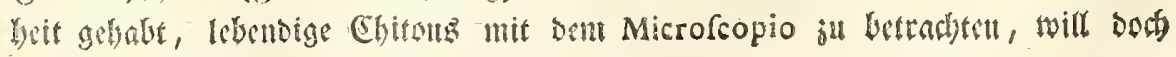
tentacula fpuria ben ituen bemertht baben.

Obi. I4). Dargenvillens Zoomorphofe pag. 64. 


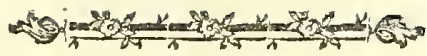

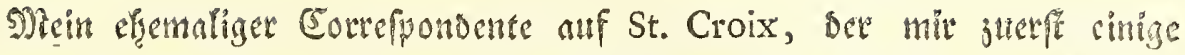

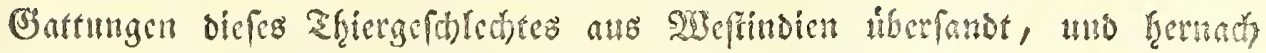

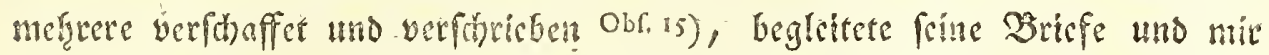

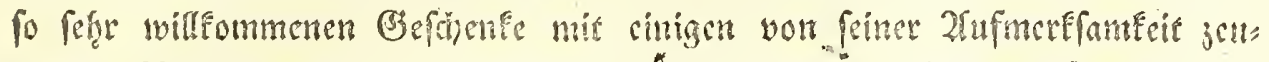

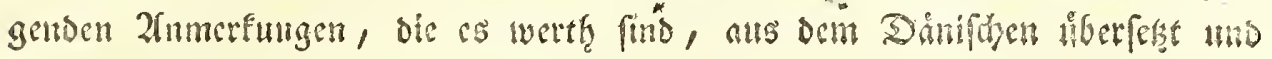
befmuter gematibt ju wersen. Saier fino fie:

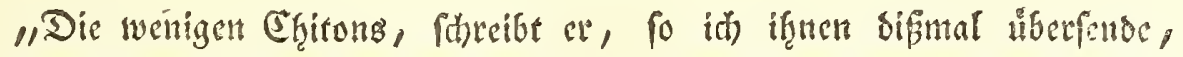

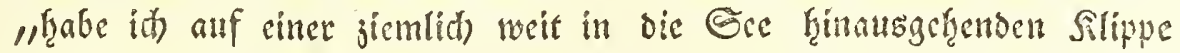

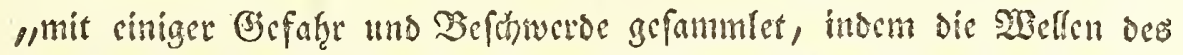

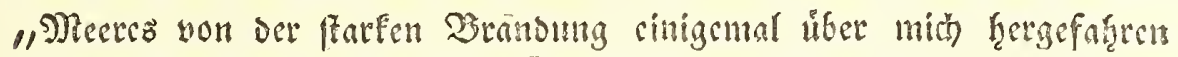

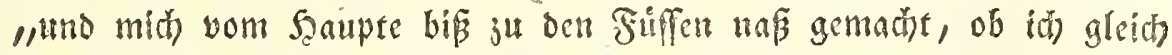
"anf ciner folthen Grelle biefer Ferfonglippe meinen Etand gefrat,

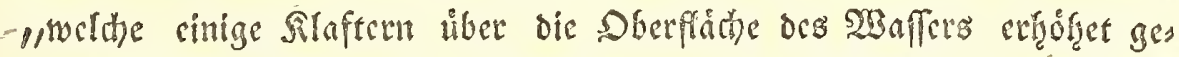

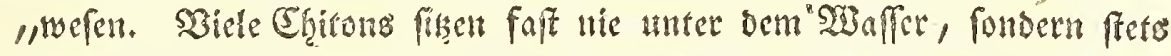

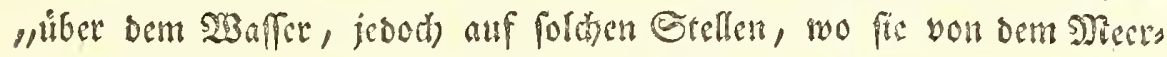

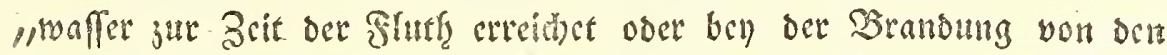

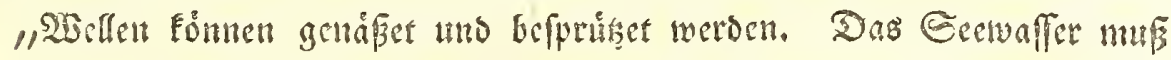

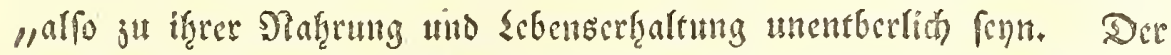

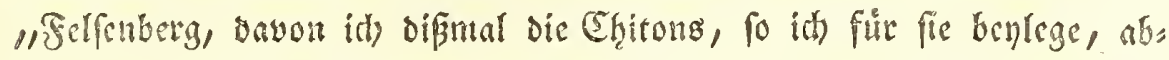

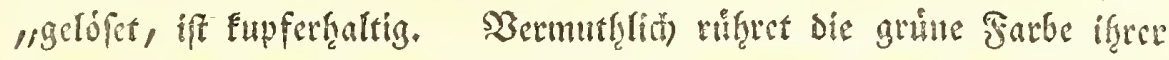
"Sd)ale jum Sfreil mit Daţer. Biele unferee Dirger uno Ereolen

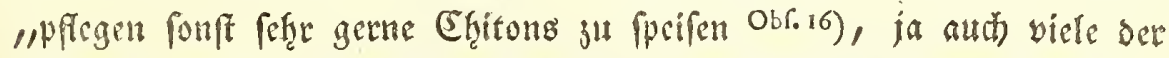

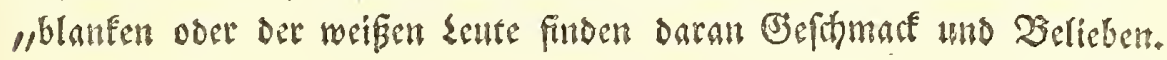

"2rileits

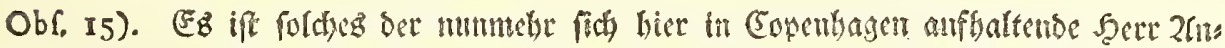

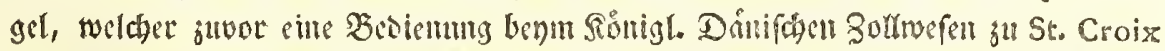

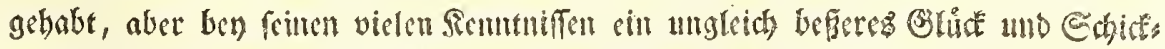

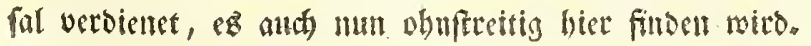

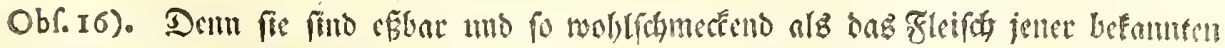

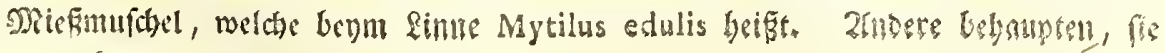
fodmeteftent wie 3rufern. 


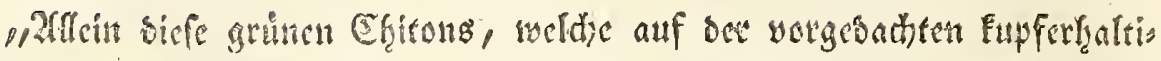
"/gen Felfentlipe veffiren, verabfacuet ein jeder, weil fie niemand

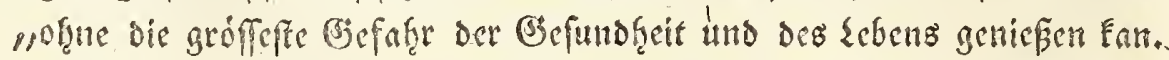

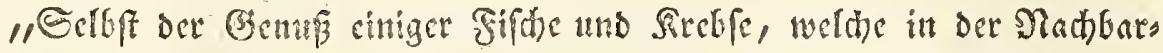
nfibaft biefes felfens gefangen werben, hat manchen seuten ein faft "tootlides Erbechen verurfachet."

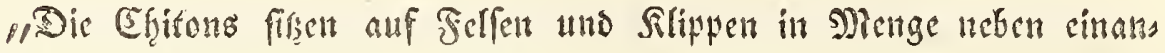

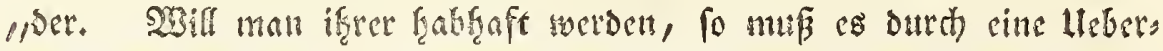

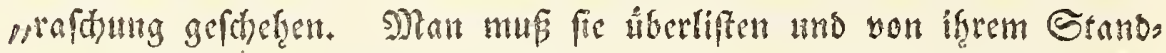

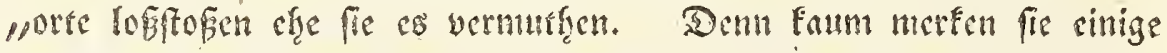

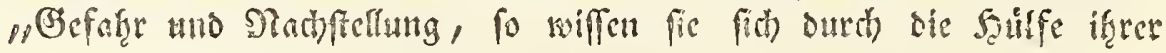

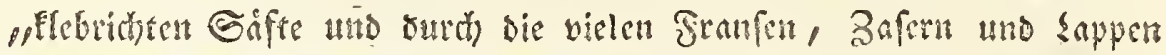

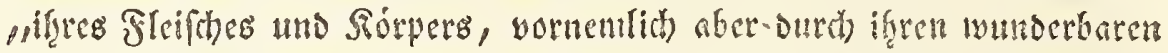

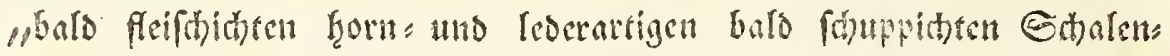

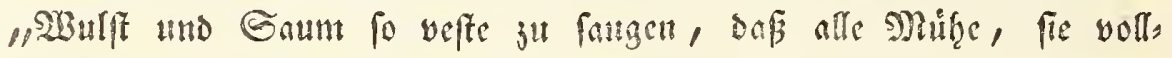

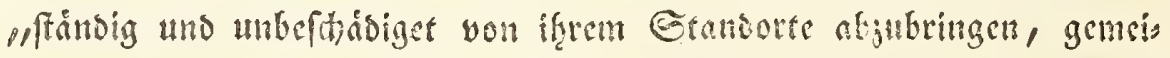

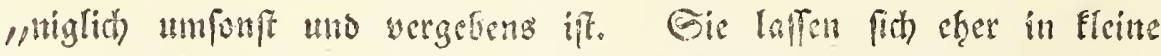

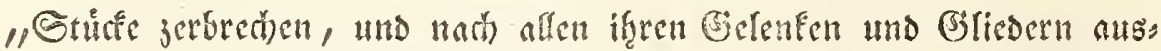

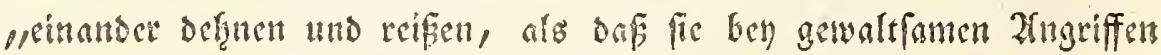
"poutwillig nathgeben wno lofilaffet foliten."

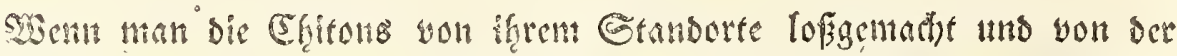

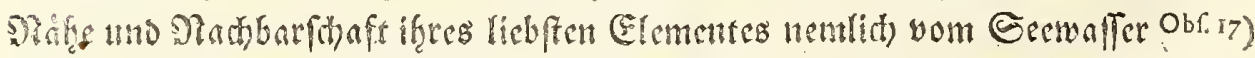
enfermer, to fornten fie troth wohl cime Beithang leben, fid bewegen uns

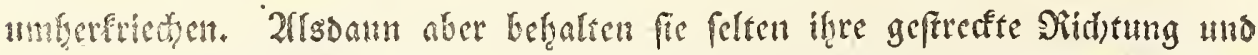

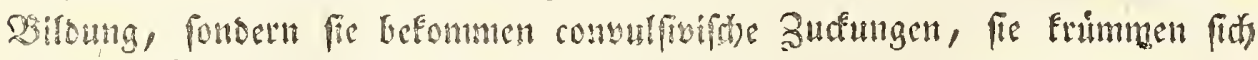

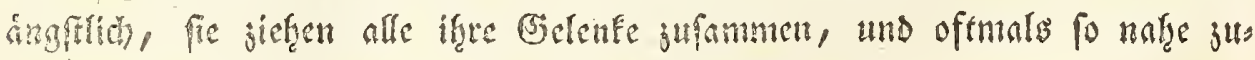
Cammen, Dafi ifere Form bey nohe ciner Sugel gleidbet.

Dic

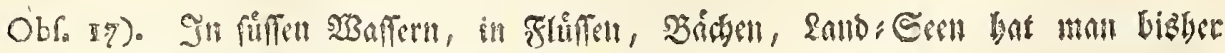

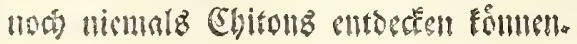




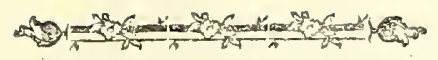

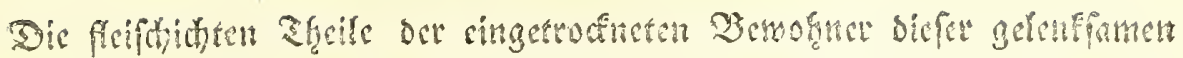

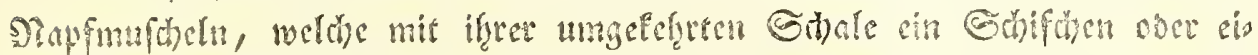

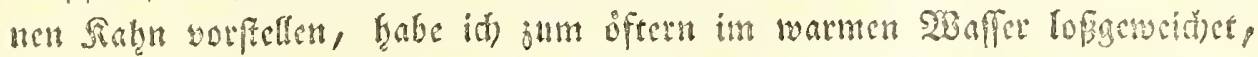

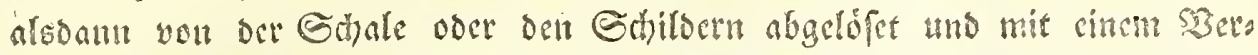

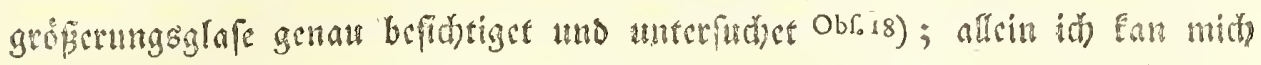

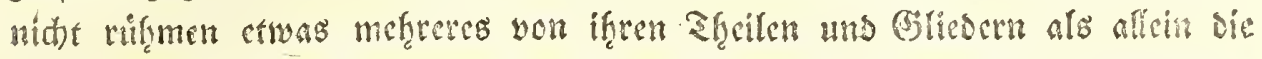

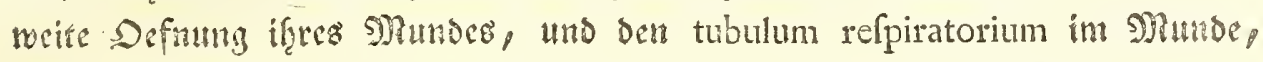

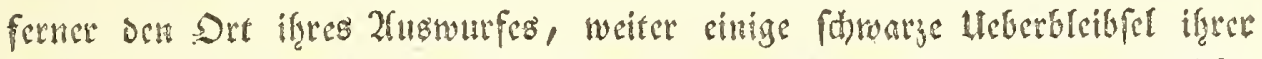

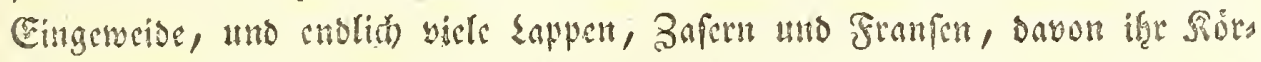

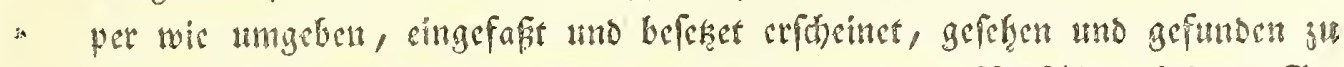

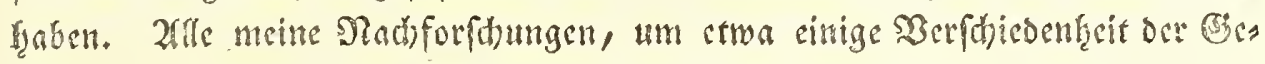

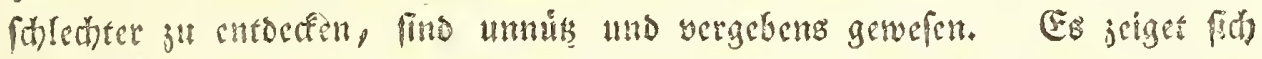

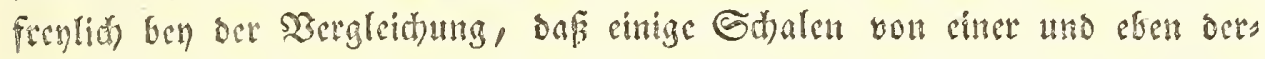

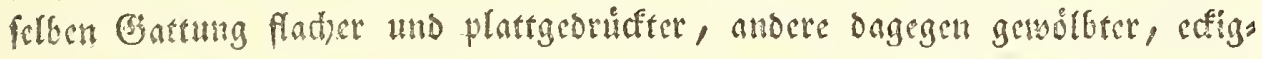

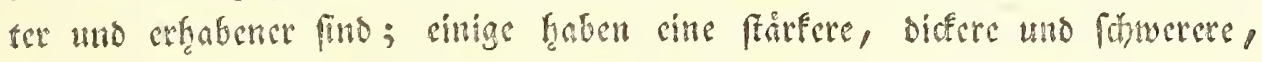

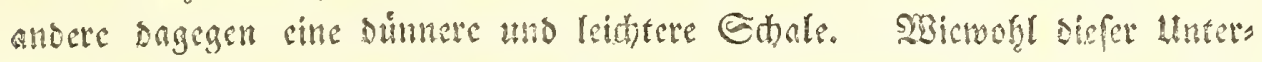

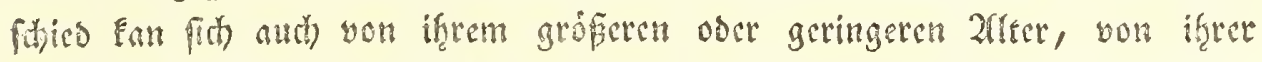

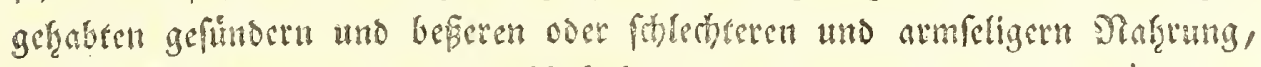

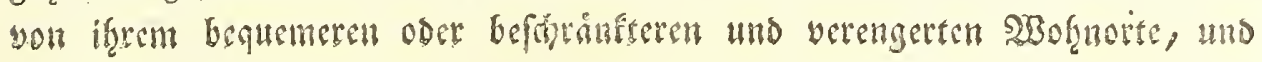

4ot

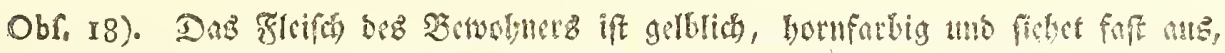

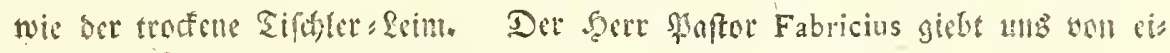
Jim (Ebitoin in finer Fauna Groenlandica folgenbe Beffereillung pag. $42 \mathrm{I}$ : Ver. mis ochreus oblongus, antice rotundatus, poftice attenuatus, more limacum pedem crafum habet, et capite inftrufus eft femiorbiculari poftice neane truncato, angulis tamen lateralibus produlis in tentacula 2 fpuria (alia enim non vidi, licet faepiffine vivos contemplatus fim) os fubtus rugofun, cruftaceum, denticulis internis. Super caput fubftantia carnofa fubrubra, per quam sanalis de orificio in inteftina ducitur, - Inteftina deinde nigra contortupli. cata fequuntur usque in anum qui fupra caudam tuberculo perforato fe prodit, prolongata. Lamellae etiam pingues croceae vel ochreae fine dubio he. paticae pone inteftina iacent. Superne in dorfo nervi plures in peripheriam teftae duati valvulas cum verme coniungunto 


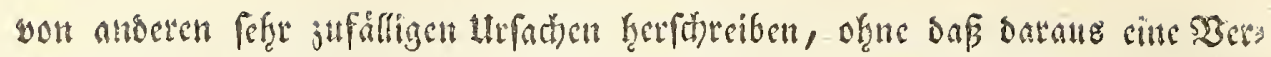

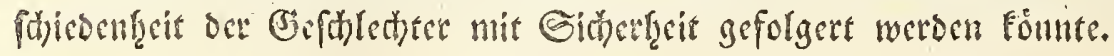

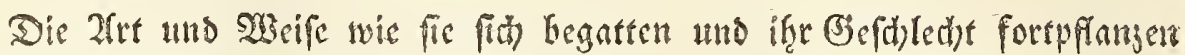

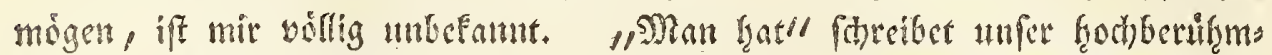

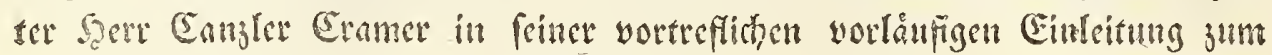

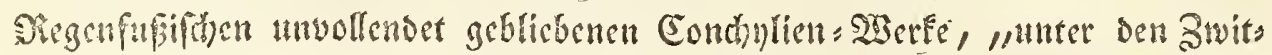

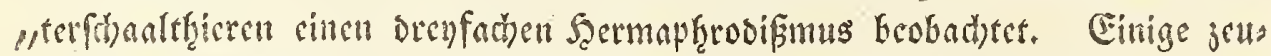

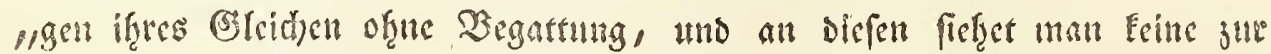

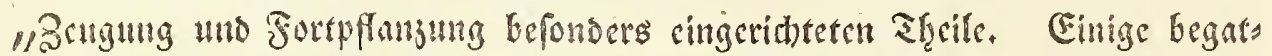

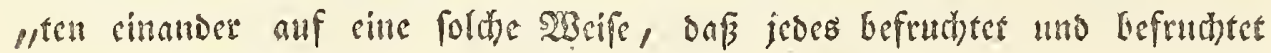

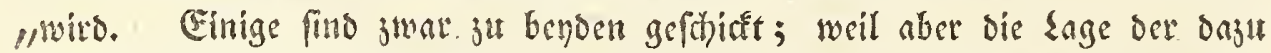
"Mothigen Schcile fo befhaffen ift, Daf nidht bevoe Sandlungen jugleich vor"

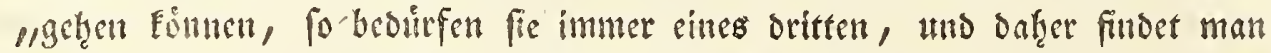

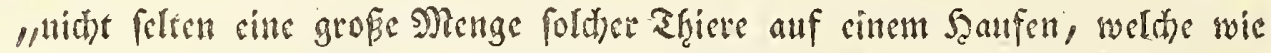

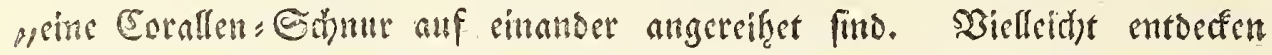
"bic Daturforfater nod) eine vierte 2(re von 3wittern, weld)e fich ourd bes "fonders Daju befrimmite Sfecile felbft begatten." 23elebe 2lut von Sacrmas phrobifmus mun bey unferen Chitons anjunef̧men fey, moggen andere, welde

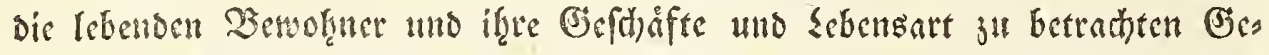

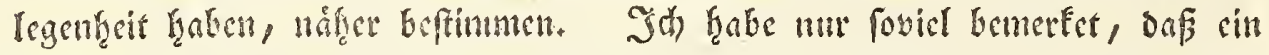
Chiton unter ocn meinigen jum offern mit feiner Sdale auf cinem anocrn

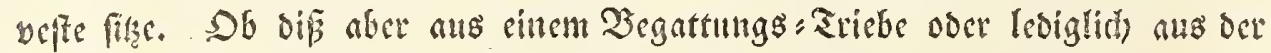
(b) зu beftimmen.

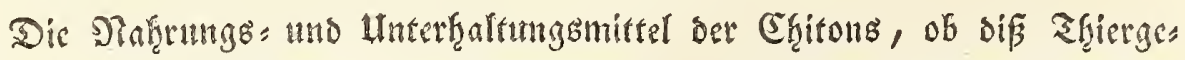

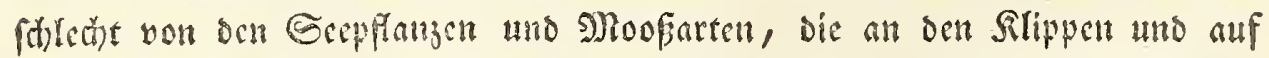
ben Felfen wadbfen, oder von Eleinen Sectwurmern, Maden und S̈nfecten Icbe, habe id nicht erfahecen noch erfragen Eơnen.

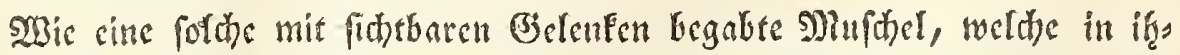
ret ganjen 2fnlage und 3 auant fo bemundernswilgig ift, uno son der weifs. heits 


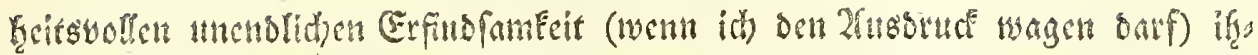

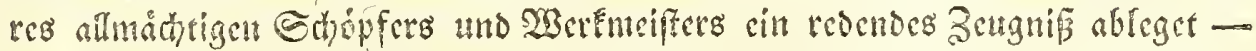

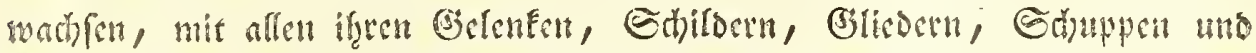

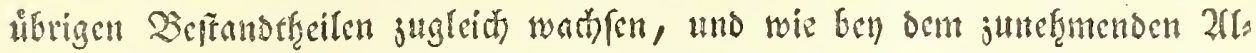

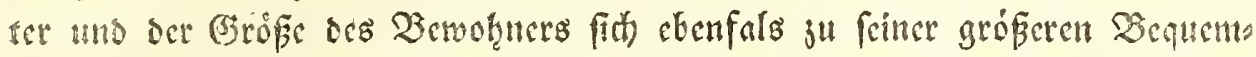

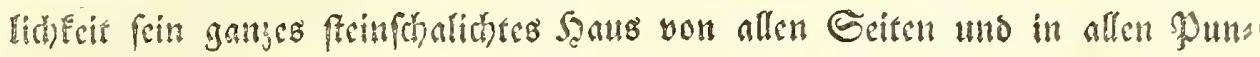

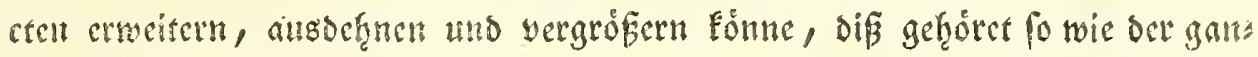

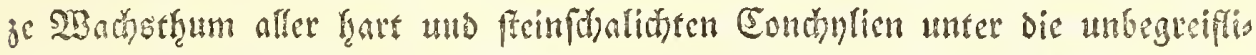

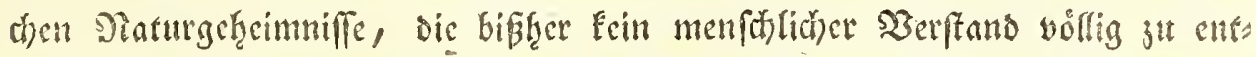
fiegein uno ju ergrimben fähig uns im Gtande gewefen. 2(uch bey dent ans

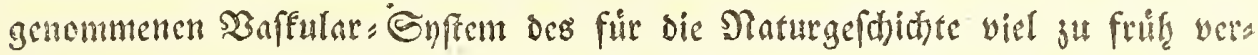

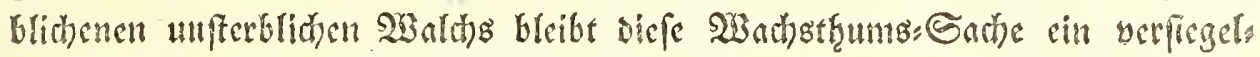
tes Befreimnis, das woht fo bals nithe entfiegelt werden módbet.

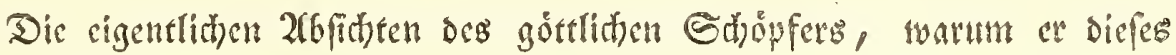

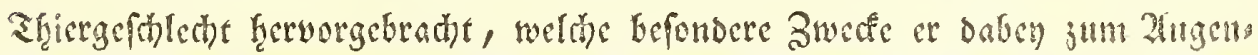

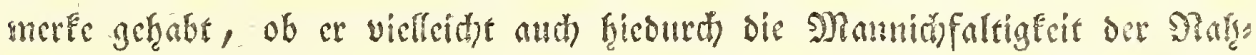

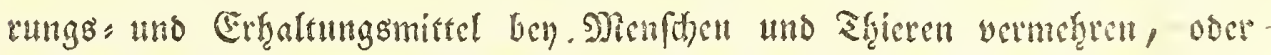

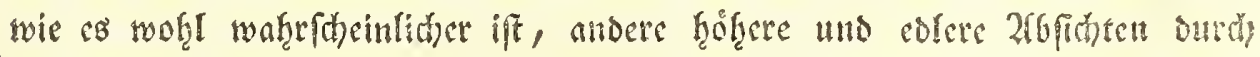

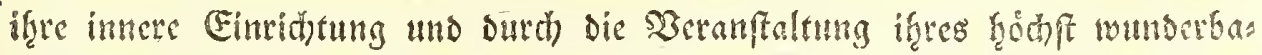

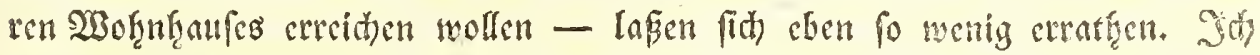

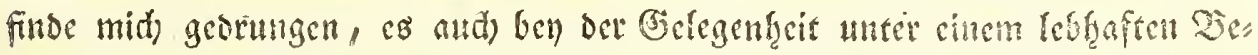

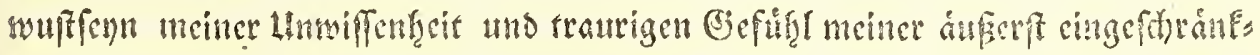

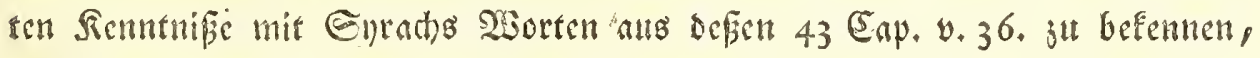
wit fehen won feinen göttionen Werten ogs wenigfe, wit errathen. von feinen 2lbfidten gemeiniglict) nur die teinfen und geringfen,

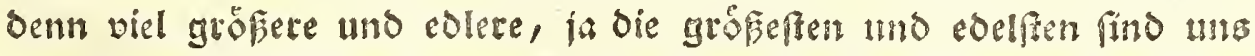

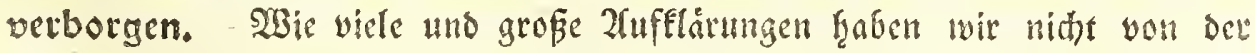

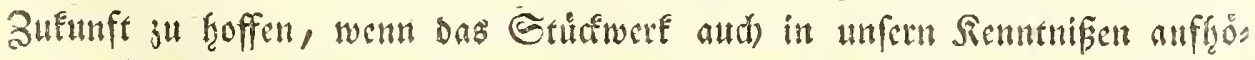
ren und Das Bolfommene fonmen wiro? wenn wir bicles nitht mefre wie

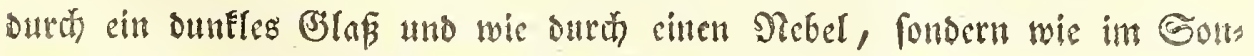

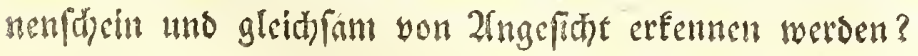




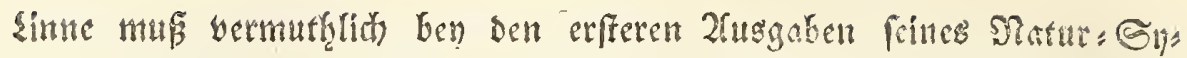

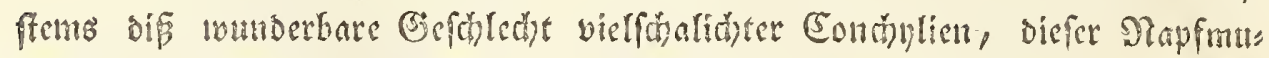

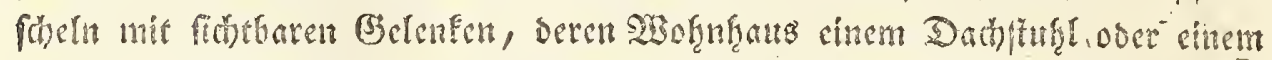

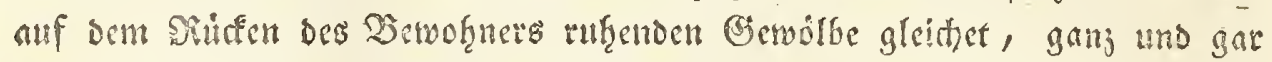

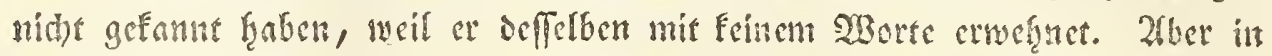

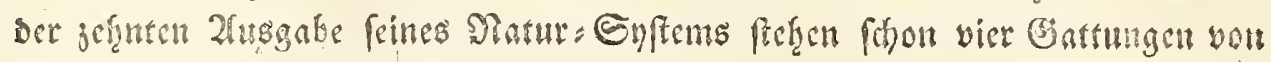
Critons, nemlid oce

Chiton hifpidus, welder nat fedps Gethiloer haben foll;

Chiton tuberculatus, Deffen Sdyale mit fieben Belenten verfes helt ifi:

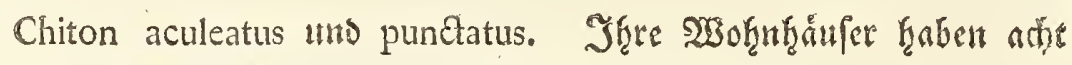
Guilder.

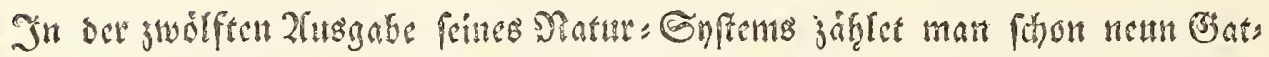

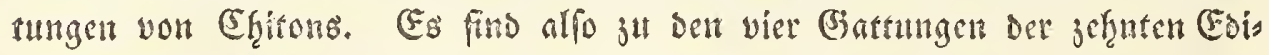
tion 110 d) finf neut hínzugefommen, nemlich Chiton fafcicularis; fquamofus,

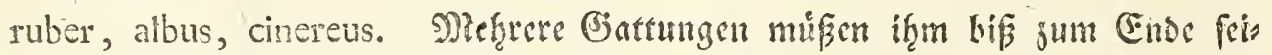

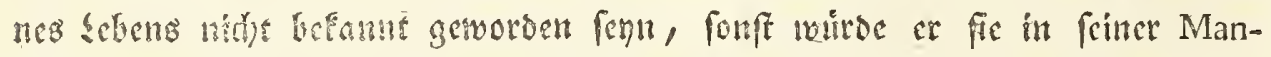

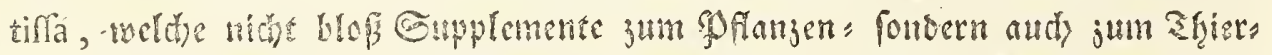

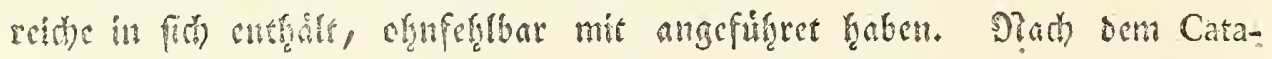

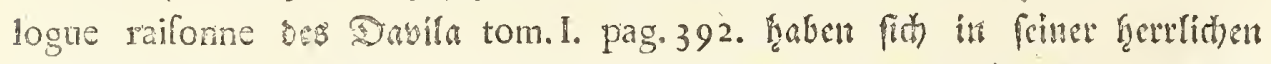
Sommlung is attoctefout Ofcabrions befunden, davon biejenigen aus chili

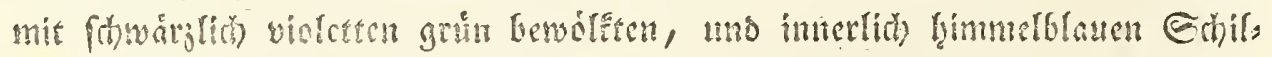

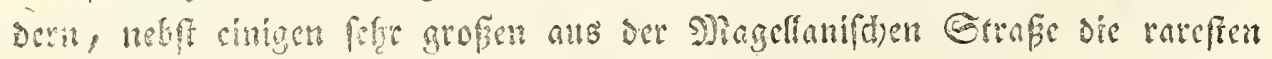

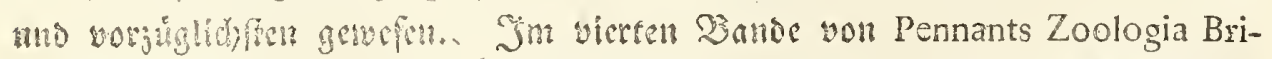
tannica pag.60.61. Reḩen bies Gottungen von Cfitens, die inggefommt an

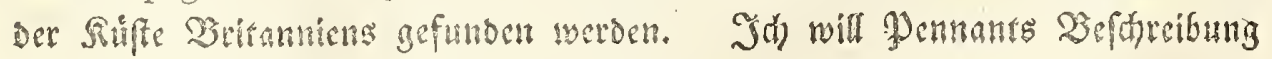

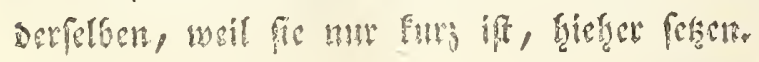

Multi- 


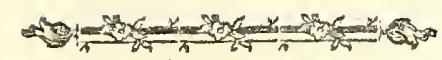

Multivalve Shells

1. Chiton crinitus. Angl. Hairy. Ch. With feven valves; thick fer with Thort hairs; five eighths of an inch long. Inhabits the fea near Aberdeen

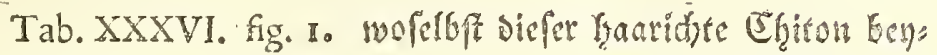
bes in feiner motrinliden Gefalt mo fęre vergrófert vorgefiellet woroch.

2. Chiton marginatus. Angl. Marginated. Ch. With eight valves; with a ferrated reflected margin, Imooth; fize of the figure tab. XXXVI, fig. 2. Inhabits the fea near Scarborough.

3. Chiton laevis. Angl. Smooth. Ch. with eight valves; quite fmooth, with a longitudinal mark along the back; a little elevated. Size of a wood-loufe. Tab. XXXVI. fig. 3. Inhabits the fhores of Loch Broom in Weft Rofl-fhire.

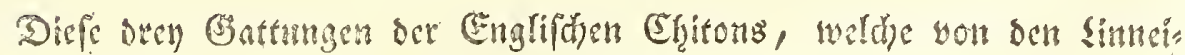

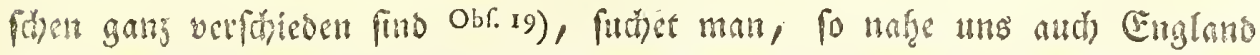
fieget, in oen Gieftgen Condiglien= Sammlungen vergebens. 2ruct von oen

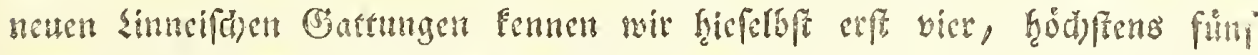
(B) nttungen, nemlidi) ben Chitonem fquamofum, rubrum, album, cinereum,

D 3

uns

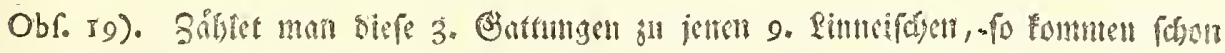

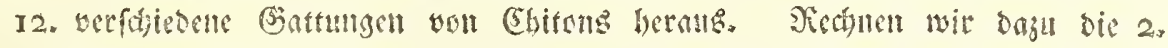

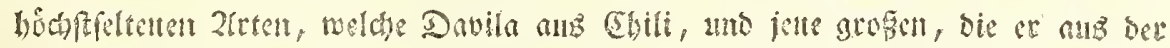

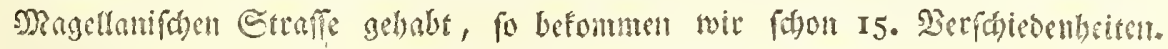

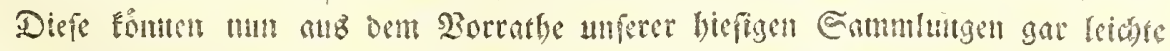

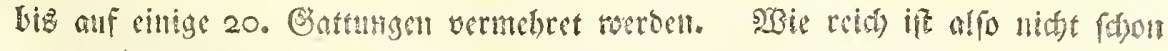

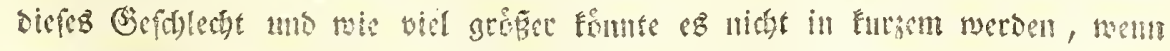

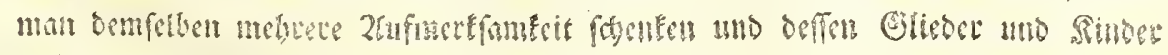
rechs anfiudtan moitte. 


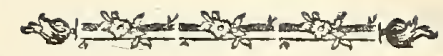

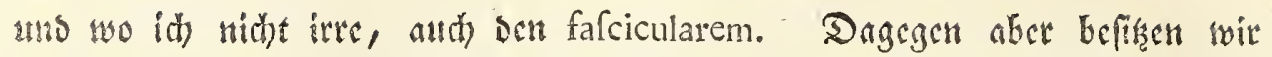

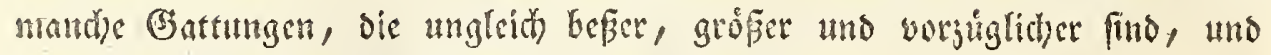
weder sem sime nody sennant befant worben.

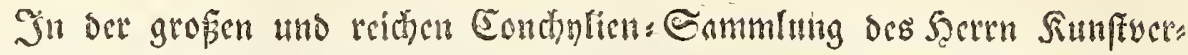
roalter Spenglers liegen oreigefen verfhiedene Gattungen von Cfitons, uno

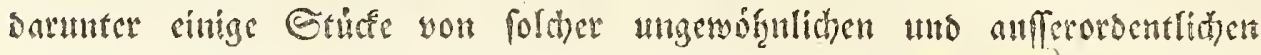

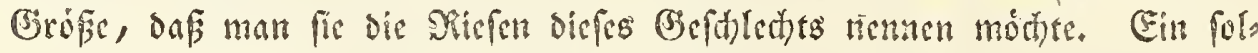
wer Efriton ift 3 . E. vier uns einen halben Zoll breit and $2 \frac{3}{4}$ Zoll lang.

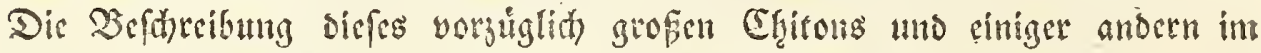

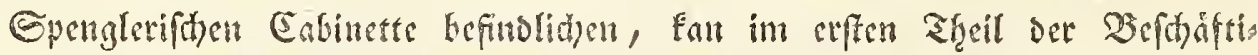
gungen naturforfhender Freunde jut Berlin, pag. 317 feq. nadbgelefen wers

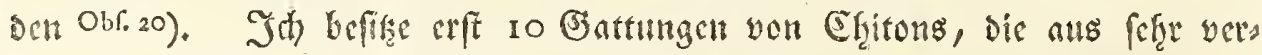
fulesenen SBeltgegenden her ftammen, nemlid) vom Borgebirge Der guten Sofnung, aus oer Mingellanifhen Etrafe, aus oem rothen Mecre, vou

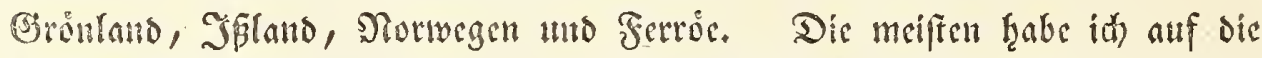

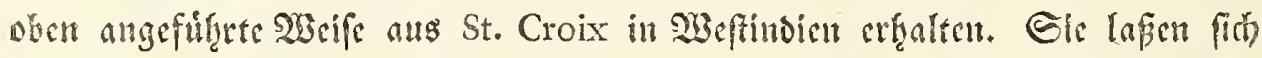

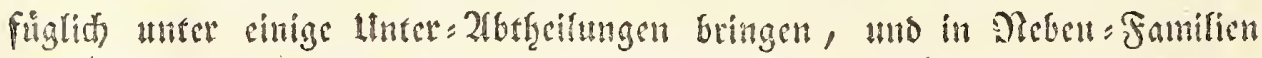
sotheilen. Denn einige find glatt uno gläjent, andere oagegen rant, volfer Streifan mo theifs atfobenen theils verteften \$uncten. Einige wers

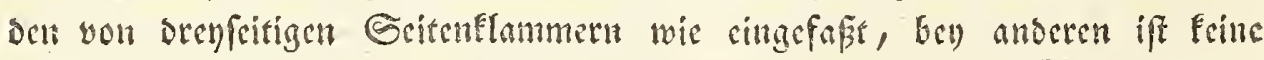

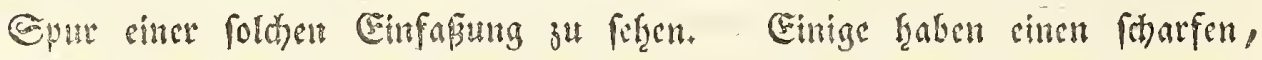

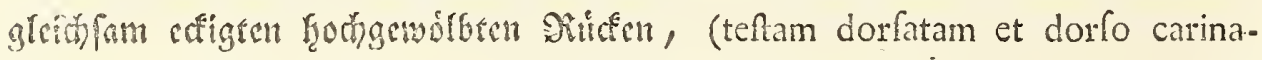
tam, une côte plus aiguë,) bey anderen Ecmerfet man cine gleidfan flact)

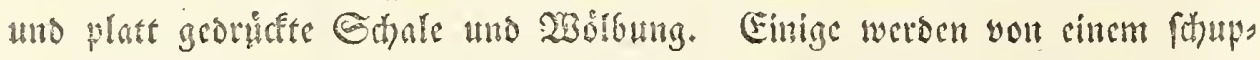
pibten Sbalenfaum, von cincm limbo fquamulis ovatis minutifimis imbricatim locatis referto et obfito, saranf viclmals foncencife ober sunfergraue Dinder

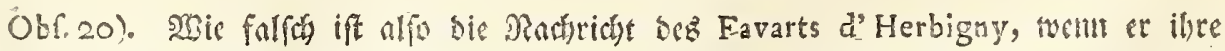

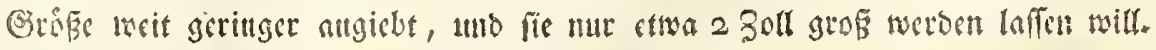
Les oscabrions peuvent avoir depuis fept ou huit lignes de longueur jusqu' a plus de deux pouces fur moitié moins de largeur, Diktion, tom. 3. pag. 5\%. 
Bänoer uns Feloet abwebfeln, umgeben. 2(ndere aber haben ftate Deffen mur cinen biden fleifhidten bornartigen Ebalenfaum, cine membranam coriaceam feu limbum carnofum, uns ermangelit afler Gotnpen. Dicfen

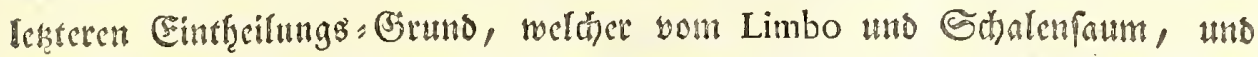

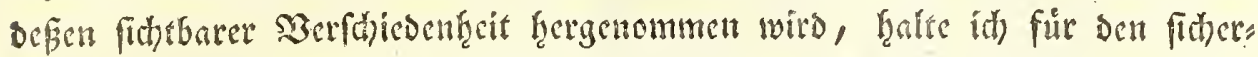

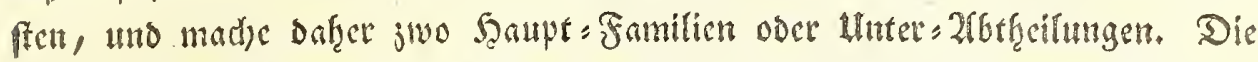
enfere entfált biejenigen Ehitons, weld)e cinen limbum fquamulis imbricasum haben. Daf̧in gefioret von jenen auf ber Supfertafel abgebilocten

Fig. I. Chiton fquamofus ex Mufeo Spengleriano. MRinte Erems plare fint vid flciner. Habitat in Promontorio bonae Spei et in mari Americano.

Fig. 2. lit, $a$, et b. Chiton fafcicularis.

Der crfte gefioret der Epenglerifhen Eammlung. Er hat glatte oreis foitige Silantmern und Felder, mit einigen wenigen Streifen und Bertiefuns gen. Den andern habe idh aus bem 2roriatifthen Mece befommen. Er trat

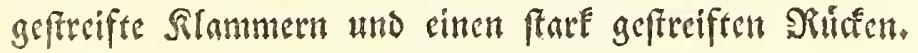

Fig. 3. Chiton fcaber variegatus. Ind. Occid. Sd) habe auth feine innere Structur vorftellen laffen.

Fig. 4. Chiton laevis variegatus. Habitat ad littora Infulae St. Crucis Ind. Occid. In ber andern Figur fiefet man Den eingetrodneten Bewohner mit sem tubulo refpiratorio.

Fig. 5. Chiton marmoreus ab Infula St. Thomae.

2lsoann folgen folche Chitolis, welthe limbum carneum et coriaceum faben, als:

Fig, 6. Chiton piceus e mari rubro. Doch miro diefe שூattumg ebenfalls auf St. Croix gefunden. 
Die mehreften, fo ich von biefer 2fre befise, find aus Seftindien. In

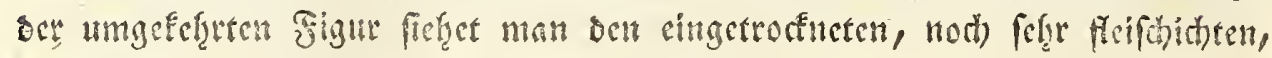
Bewof̧ner. Derienige bey lit. b. hat nur 7 , und Der bey lit. c. je mur 6 .

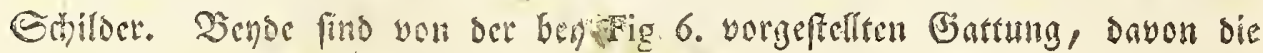

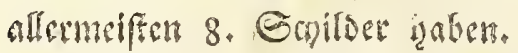

Fig. 7. no, " "he ageilanicus rariffmus ex Freto Magellanico. inrerua tructura praecedentis.

Fig. 8. Chiton ruber. Habitat in rupibus maris Groenlandici, Islandici, Norwagici.

Fig. 9. Chiton slbus, feu cineress "nn.? ex Oceano feptentrionali.

Fig. 10. Chiton maximus a Promontorio bonae Cpei, ex Mufeo Lorenziano.

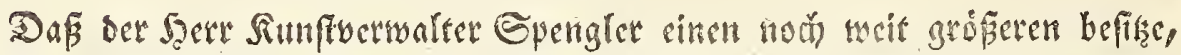

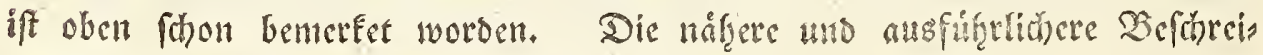
bung aller bicfer uno vider andern Gattungen von (Ggitons Ean ith hier

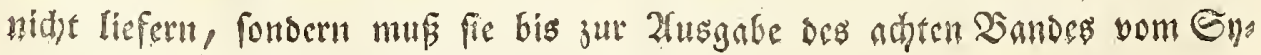
ftematifigen Condbylien. Eabinst verfparen.

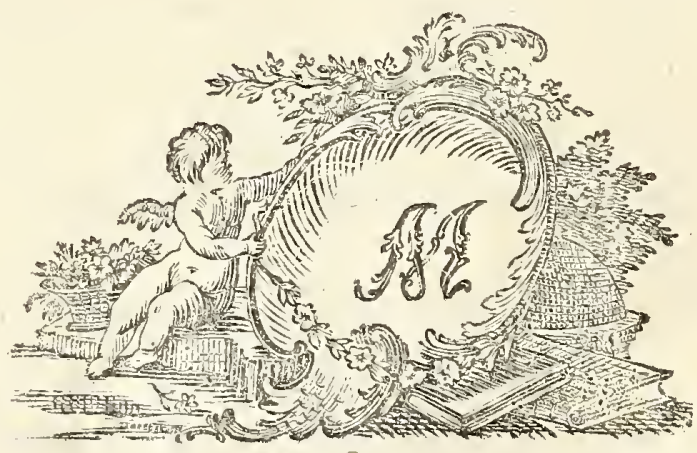




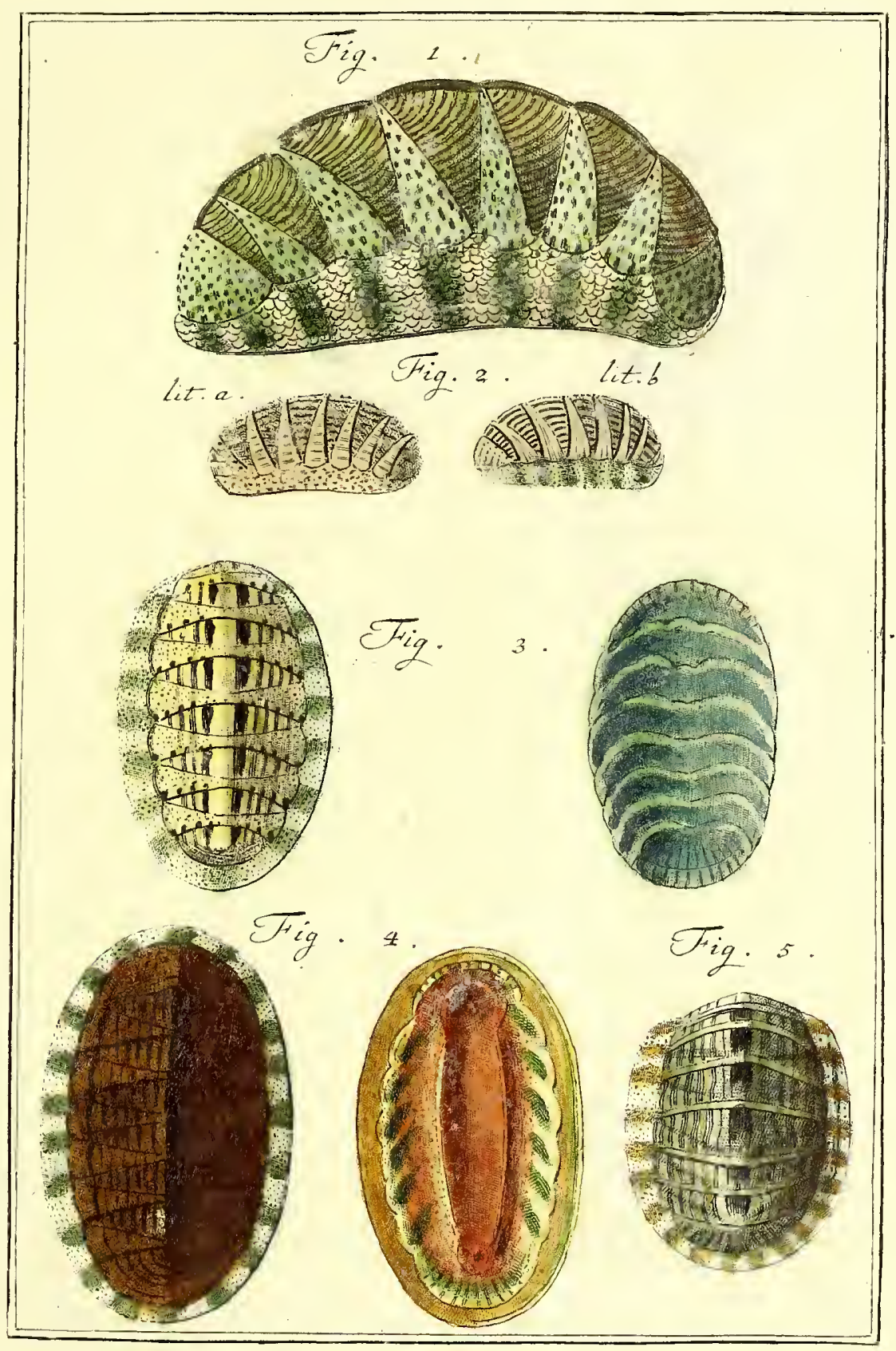





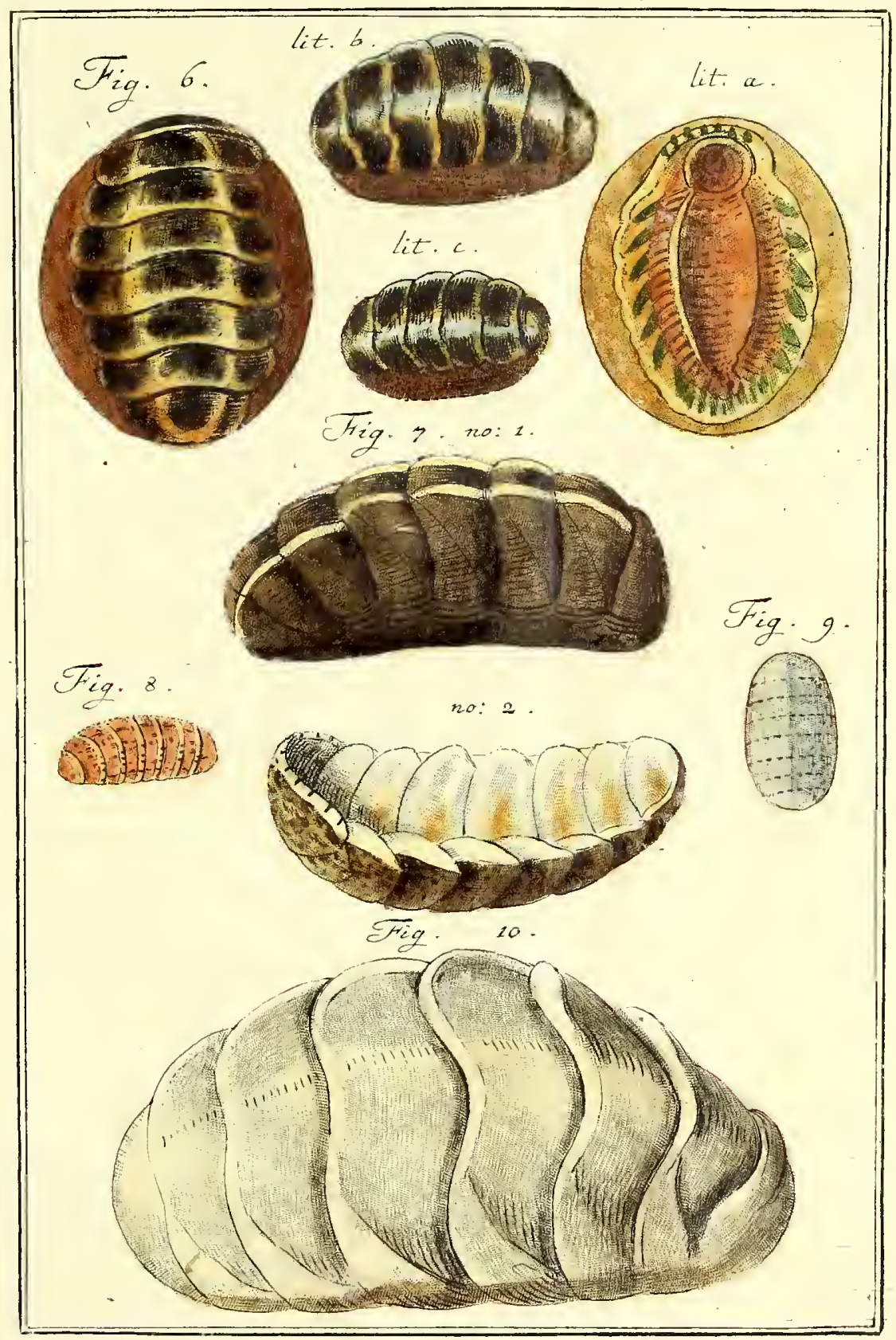


,

- 

